Earth Interactions - Volume 24 (2020) - Paper No. 1 • Page 1

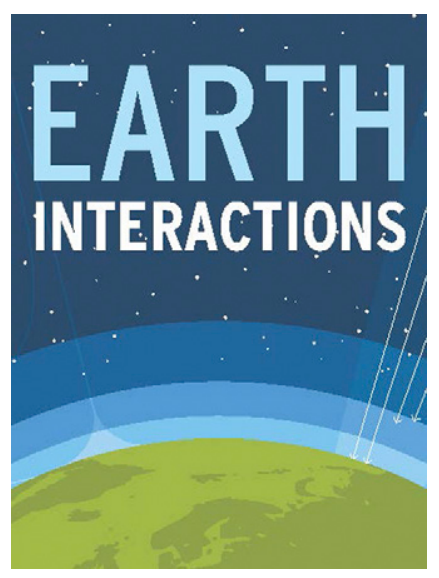

(C) 2020 American Meteorological Society. For information regarding reuse of this content and general copyright information, consult the AMS Copyright Policy (www.ametsoc.org/PUBSReuseLicenses).

\title{
Impacts of Irrigation on Summertime Temperatures in the Pacific Northwest ${ }^{\circ}$
}

\section{Patricia M. Lawston ${ }^{\text {a }}$}

Earth System Science Interdisciplinary Center, University of Maryland, College Park, College Park, and Hydrological Sciences Laboratory, NASA Goddard Space Flight Center, Greenbelt, Maryland

\section{Joseph A. Santanello, Jr.}

Hydrological Sciences Laboratory, NASA Goddard Space Flight Center, Greenbelt, Maryland

\section{Brian Hanson}

Department of Geography, University of Delaware, Newark, Delaware

\section{Kristi Arsensault}

Science Applications International Corporation, McLean, Virginia, and Hydrological Sciences Laboratory, NASA Goddard Space Flight Center, Greenbelt, Maryland

Received 15 July 2019; in final form 5 November 2019

Supplemental information related to this paper is available at the Journals Online website: https://doi.org/10.1175/EI-D-19-0015.s1.

${ }^{\text {a }}$ Corresponding author: Dr. Patricia M. Lawston, patricia.m.lawston@ nasa.gov 
Earth Interactions - Volume 24 (2020) - Paper No. 1 • Page 2

\begin{abstract}
Irrigation has the potential to modify local weather and regional climate through a repartitioning of water among the surface, soil, and atmosphere with the potential to drastically change the terrestrial energy budget in agricultural areas. This study uses local observations, satellite remote sensing, and numerical modeling to 1) explore whether irrigation has historically impacted summer maximum temperatures in the Columbia Plateau, 2) characterize the current extent of irrigation impacts to soil moisture (SM) and land surface temperature (LST), and 3) better understand the downstream extent of irrigation's influence on near-surface temperature, humidity, and boundary layer development. Analysis of historical daily maximum temperature (TMAX) observations showed that the three Global Historical Climate Network (GHCN) sites downwind of Columbia Basin Project (CBP) irrigation experienced statistically significant cooling of the mean summer TMAX by $0.8^{\circ}-1.6^{\circ} \mathrm{C}$ in the post-CBP (1968-98) as compared to pre-CBP expansion (1908-38) period, opposite the background climate signal. Remote sensing observations of soil moisture and land surface temperatures in more recent years show wetter soil $(\sim 18 \%-25 \%)$ and cooler land surface temperatures over the irrigated areas. Simulations using NASA's Land Information System (LIS) coupled to the Weather Research and Forecasting (WRF) Model support the historical analysis, confirming that under the most common summer wind flow regime, irrigation cooling can extend as far downwind as the locations of these stations. Taken together, these results suggest that irrigation expansion may have contributed to a reduction in summertime temperatures and heat extremes within and downwind of the CBP area. This supports a regional impact of irrigation across the study area.
\end{abstract}

KEYWORDS: Atmosphere-land interaction; Hydrometeorology; Soil moisture; Numerical analysis/modeling

\title{
1. Introduction
}

Irrigation has the potential to modify local weather and regional climate through a repartitioning of water among the surface, soil, and atmosphere with the potential to drastically change the terrestrial energy budget in agricultural areas (Qian et al. 2013). Vegetation cover and soil moisture primarily control water and energy fluxes from the surface into the planetary boundary layer (PBL), providing a pathway for irrigation to affect PBL growth and entrainment, and ultimately clouds and precipitation (Alter et al. 2015; Harding and Snyder 2012). This means the effects of irrigation could be particularly important in semiarid regions where irrigation not only affects soil moisture, but also enables the thriving of nonnative crops and vegetation.

One such semiarid, irrigated region exists in the Pacific Northwest, United States. The Columbia Basin Project (CBP) is a federally managed series of dams, reservoirs, and canals that deliver irrigation water from the Columbia River to central Washington and have made this otherwise desertlike landscape into an agriculturally productive region. The project was initially authorized in the early 1930s by U.S. President Franklin D. Roosevelt, but the first deliveries of irrigation water ultimately occurred between 1948 and 1952, beginning decades of explosive growth of irrigated agriculture in the region (Simonds and Linenberger 1998).

The main objective of this work is to determine the impact of irrigation on summertime maximum temperatures and extremes in the vicinity of the Columbia 
Earth Interactions - Volume 24 (2020) • Paper No. 1 • Page 3

Basin Project in Washington, United States. This goal is achieved through analysis of daily climate records, remote sensing data, and a series of high-resolution model simulations that explicitly represent irrigation and use realistic initial and boundary conditions. The semiarid climate of central Washington is typical of many other irrigated regions in the western United States (e.g., California Central Valley, Snake River Valley, Idaho) and around the world (e.g., northern Spain). Thus, by quantifying the impacts of widespread irrigation implementation on the ambient temperature over this region, the role of human practices that impact the water and energy cycles can be understood. This is particularly important as these regions tend to be highly dependent on irrigation for food security and are therefore particularly vulnerable to episodes of drought and water scarcity. The paper is organized as follows: section 2 describes relevant background information about irrigation impacts on weather and climate, as well as the history of the Columbia Basin Project. Section 3 presents the datasets and methods employed and section 4 describes the results of the observational and modeling analyses. A discussion of the limitations and future directions is presented in section 5, followed by conclusions in section 6 .

\section{Background}

\subsection{Irrigation impacts on temperature}

Irrigation increases soil moisture, a fundamental state variable connecting the water, carbon, and energy cycles (Entekhabi et al. 2004). Soil moisture is the first "link" in the process chain that relates changes in soil moisture to clouds and precipitation via feedbacks and interactions with surface fluxes, near-surface temperature and humidity, and PBL growth and entrainment (Santanello et al. 2018). Although the impact of irrigation on soil moisture and fluxes is relatively well understood, as wetter soil resulting from irrigation partitions more energy into latent than sensible heat fluxes (Adegoke et al. 2003; Qian et al. 2013; Lawston et al. 2015), to what extent these flux changes impact air temperature and humidity is uncertain. For example, estimates of the irrigation cooling effect in California's Central Valley alone range from 1.1 to 8.0 K (Huang and Ullrich 2016; Kueppers and Snyder 2012; Yang et al. 2017; Sorooshian et al. 2011). At least some of the variability in these irrigation cooling estimates can be attributed to different model configurations (e.g., type, resolution, irrigation scheme), but the variety of results underscores the need for a full examination of the feedbacks and interactions within the PBL to truly characterize the severity and downwind influence of irrigation's impact on temperature.

Modeling tends to be the method of choice for irrigation impact studies, as data availability within irrigated areas is often lacking, making observation-focused work more difficult. Nevertheless, several studies have been able to use station and other data to show an irrigation cooling effect. Lobell and Bonfils (2008) used a linear regression model to relate irrigated area trends with changes in maximum and minimum temperatures in California's Central Valley, estimating up to $5^{\circ} \mathrm{C}$ cooling in the most heavily irrigated areas. Other research has shown an irrigation cooling effect in the Texas Panhandle of $1{ }^{\circ} \mathrm{C}$ on damp, cool days and $2{ }^{\circ} \mathrm{C}$ on dry, hot days (Barnston and Schickedanz 1984) and an approximately $1{ }^{\circ} \mathrm{C}$ cooling was 
Earth Interactions - Volume 24 (2020) • Paper No. 1 • Page 4

found in Nebraska following irrigation expansion (Mahmood et al. 2004, 2006). Other studies, at the global scale, indicate the role of irrigation in assimilation systems. For example, Tuinenburg and de Vries (2017) showed positive correlations between the soil moisture additions to the ERA-Interim and annual cycles of irrigation, positing that irrigation may act to cool the screen-level observations (2-m temperature and humidity) in heavily irrigated areas, especially in regions of little precipitation and intensive irrigation.

Irrigation's first impact on the atmosphere is at the local scale, but large-scale, perennial irrigation activities can influence climate on seasonal and longer time scales. The greatest growth in irrigation occurred in the mid-twentieth century, concurrent with increases in greenhouse gas concentrations, leading some to hypothesize that past irrigation expansion may have mitigated anthropogenic warming (Kueppers et al. 2007; Lobell et al. 2009; Cook et al. 2010). In fact, Thiery et al. (2017) concluded that irrigation has reduced exposure to heat extremes in the past, but a recent slowdown in irrigation intensity could contribute to greater heat stress in the future. This is supported in part by Kang and Eltahir (2018), who showed that the increased frequency of heat waves driven by climate change, coupled with added humidity from irrigation, could pose a significant future risk to human health in the North China Plain.

\subsection{The CBP}

The CBP is managed by the U.S. Bureau of Reclamation (USBR) and was one of the first and largest projects undertaken in its mission to encourage development in the western United States. The original CBP proposal called for the irrigation of approximately 1 million acres of dryland in the Columbia Plateau, but complications and escalating costs restricted the actual irrigated acreage to about 670000 acres [Columbia Basin Development League (CBDL) 2018]. The construction of the Grand Coulee Dam, completed in 1942, created the reservoir and hydroelectric power necessary to provide irrigation to the Plateau. The pumping stations and canals were completed next, allowing the first water delivery from the Columbia River to about 5400 acres in 1948, and the first water pumped from the Grand Coulee Dam to around 66000 acres in 1952 (CBDL 2018). In the 1960s, many within the original CBP limits who were promised irrigation water by the project were issued groundwater permits instead. Today, irrigated agriculture still thrives as the area produces high-value crops, such as cherries and mint, and boasts an abundance of wineries (USBR 2008).

The dramatic increase in irrigated land made possible by the CBP spurred some of the first studies investigating irrigation's potential impact on weather and climate. In the 1970s, a series of correspondences appeared in Science between Fowler and Helvey (1974) and Eddy (1975) in which the two groups disagreed about whether irrigation had impacted climate in the Columbia basin. Stidd implied that irrigation water from the CBP is recycled at least once as rainfall, with the greatest precipitation likely falling in the foothills of the adjacent mountains. Results from Stidd's earlier work (Stidd 1967) showed that July and August rainfall in the Columbia Plateau is sensitive to additional moisture input from local evapotranspiration. In contrast, Fowler and Helvey (1974) concluded that 
Earth Interactions - Volume 24 (2020) • Paper No. 1 • Page 5

widespread climatic effects due to irrigation are likely small, finding changes in July minimum, maximum, and mean temperature and precipitation trends were minimal when comparing pre- and postirrigation periods (i.e., 1924-50 and 195170, respectively).

We aim to revisit and comprehensively investigate the role of Columbia Basin Project's irrigation on temperature, aided by 30 additional years of in situ data, and new modeling and satellite technologies. In particular, we use in situ observations, satellite remote sensing, and numerical modeling to 1) explore whether irrigation has historically impacted summer maximum temperatures in the Columbia Plateau, 2) characterize the current extent of irrigation impacts to soil moisture (SM) and land surface temperature (LST), and 3) better understand the downstream extent of irrigation's influence on near-surface temperature, humidity, and boundary layer development.

\section{Data and methods}

\section{1. Historical temperature data}

We use maximum daily temperature (TMAX) from the Global Historical Climatology Network-Daily database (GHCN-D; Menne et al. 2012a,b), version 3.2 , to investigate temperature trends prior to and after CBP irrigation expansion. The GHCN-D dataset is a collection of global, land-based daily climate records that have undergone a suite of quality checks and contains the most comprehensive collection of daily summaries currently available for the United States. There are seven GHCN stations in the vicinity of the CBP with observations dating back to the early 1900s, including Ellensburg, Waterville, Wilbur, Odessa, Ritzville, Kennewick, and Dayton (Figure 1; sites a-g, respectively). As shown in the Figure 1, most of the GHCN stations are near, but not directly within, the CBP boundaries.

Given the irrigation commencement window of 1948-52, we analyze the distribution of summertime (JJA) maximum temperatures, number of extreme heat days, and temperature trends for the 30-yr periods of 1908-38 and 1968-98, hereafter, referred to as "pre-CBP" and "post-CBP" expansion periods, respectively. These two time periods were chosen for several reasons:

1) The latter period includes the three peak decades of irrigation extent, giving sufficient time for any potential irrigation effects to ramp up.

2) There were no large data gaps during these periods for most stations.

3) Previous studies and reports on climate of the U.S. Pacific Northwest indicate that the 1968-98 period was warmer regionally than the earlier period (Abatzoglou et al. 2014; Kunkel et al. 2013). This implies that any cooling detected in the post-CBP period is not due to the background climate.

In addition to the GHCN, we analyze more recent (i.e., mid-1980s to the present) weather station observations from the USBR's Pacific Northwest Cooperative Agricultural Weather Network, called AgriMet (USBR 2016). The observations recorded at each automated site vary by station but typically include 15-min temperature and dewpoint, hourly wind speed and direction, and cumulative precipitation. We use the AgriMet data to determine the prevailing wind flow in the region and to evaluate the results of the model simulations. 


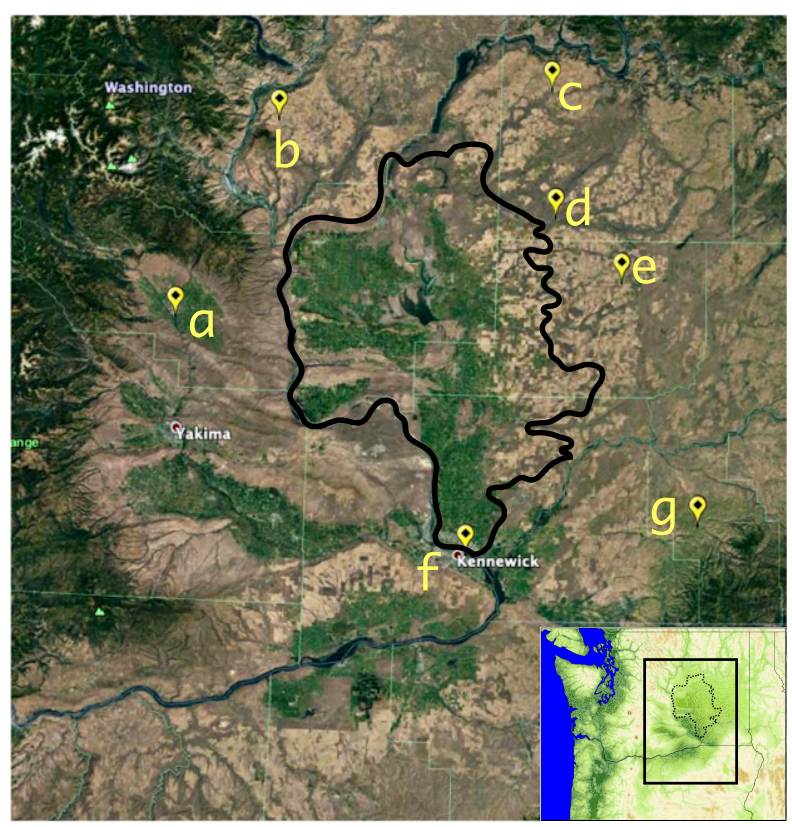

Figure 1. True reflectance image of the central Washington study area (Google Earth Pro, version 7.3.2.5776 (20 Jul 2018). Othello, Washington, United States. $46^{\circ} 46^{\prime} 51.85^{\prime \prime} \mathrm{N}, 119^{\circ} 24^{\prime} 41.01^{\prime \prime} \mathrm{W}$. Eye alt $230.13 \mathrm{mi}$. Image Landsat/ Copernicus 2018 (13 Jun 2019)). The black line marks the boundaries of the Columbia Basin Project (USBR 2008). Yellow markers and letters indicate the locations of the GHCN sites used in the analysis and are as follows (a) Ellensburg, (b) Waterville, (c) Wilbur, (d) Odessa, (e) Ritzville, (f) Kennewick, and (g) Dayton. Inset shows the study area location in relation to the northwest coast of the United States.

\subsection{Satellite remote sensing data and analysis}

Before the impacts of irrigation can be communicated to the atmosphere, the first and most direct effect of irrigation occurs to the SM and, subsequently, LST. Thus, we use datasets from two satellite remote sensing platforms to analyze regional changes to SM and LST. Although the period of record is limited compared to the historical climate network dataset, satellite remote sensing offers the advantage of spatially continuous observations. Here we analyze the near-surface $(0-5 \mathrm{~cm}) \mathrm{SM}$ from the Soil Moisture Active Passive (SMAP; Entekhabi et al. 2010) satellite and the LST from the Moderate Resolution Imaging Spectroradiometer (MODIS; Wan 2013) on board the Terra satellite. The SMAP satellite uses a passive, L-band microwave radiometer and a retrieval algorithm to estimate SM from observed brightness temperature. We use SMAP Level 3 Enhanced, version 1, soil moisture retrievals (O'Neill et al. 2018), available since April 2015 at 1-3-day temporal resolution and gridded at $9 \mathrm{~km}$ spatial resolution, but with a native resolution of $36 \mathrm{~km}$. The MODIS Terra LST, Collection 6, is used and features 1-km spatial resolution and daily temporal resolution. 
Earth Interactions - Volume 24 (2020) - Paper No. 1 • Page 7

We analyze the remotely sensed datasets by calculating the average SM from SMAP and LST from MODIS for each pixel for the month of July. In addition, yearly time series of SM and LST at irrigated and nonirrigated pixels are generated to explore contrasts over time within and outside of the irrigated regions.

\subsection{Regional modeling}

The satellite remote sensing analysis provides insight into the bulk, regional response of SM and LST to irrigation, while the GHCN-D datasets allows for longterm analysis of air temperature trends in the region. To better understand the process-level connections between irrigation, SM changes, and daily summertime weather in the study area via boundary layer processes and feedbacks that link the land surface and atmosphere, a series of regional modeling simulations are conducted.

\subsubsection{Model configuration}

The modeling systems used are NASA's Land Information System (LIS; Kumar et al. 2006), version 7.1, and NASA's Unified Weather Research and Forecasting model (NU-WRF; Peters-Lidard et al. 2015), version 8. LIS is a land surface modeling and data assimilation framework that allows users to complete long-term, land-only simulations using one of a number of land surface models (LSMs) to "spin up" surface states and fluxes (Rodell et al. 2005) on the same grid to be used by WRF. In this study, we use the Noah LSM, version 3.3 (Chen and Dudhia 2001) within the LIS framework. NU-WRF contains all features of NCAR's standard WRF Model, but includes additional physics options and the ability to run coupled simulations with LIS (herein, LIS-WRF). The LIS and NU-WRF modeling systems have proven to be effective tools for investigating soil moisture-boundary layer interactions (Santanello et al. 2011, 2013, 2019) and irrigation impacts on the atmosphere (Lawston et al. 2015, 2017).

The LIS-WRF Model configuration for this study uses two nested domains at 9- and 3-km spatial resolution centered on the Columbia Plateau in Washington and Oregon, United States (see Figure S1 in the online supplemental material). Each running domain contains $249 \times 315$ grid points and 42 vertical levels. There are 18 model levels in the $1-\mathrm{km}$ column closest to the ground, including 6 levels in the first $100 \mathrm{~m}$. The fine vertical resolution in the lower boundary is more amenable to planetary boundary layer schemes based on turbulent kinetic energy. As such, the Mellor-Yamada-Nakanishi-Niino level 2.5 (MYNN2.5; Nakanishi and Niino 2006) PBL and surface-layer schemes are used.

The landcover dataset is from the MODIS International Geosphere-Biosphere Program (MODIS-IGBP) and the greenness and leaf area index (LAI) inputs are from NCEP climatological datasets. These datasets have shown positive performance in previous studies using the Noah LSM in the LIS framework (Lawston et al. 2015). The atmospheric boundary and initial conditions in the coupled runs are provided by the analysis fields from the North American Mesoscale Forecast System (NAM) at 6-hourly intervals and $12-\mathrm{km}$ spatial resolution. Land surface initial conditions come from 3-yr, land-only Noah LSM spinups forced by data 
Earth Interactions • Volume 24 (2020) • Paper No. 1 • Page 8

from the National Land Data Assimilation System-Phase 2 (NLDAS-2; Xia et al. 2012) and the Global Data Assimilation System (GDAS), for the U.S. and international regions, respectively. Previous studies with these models and methods have shown a spinup time of 3 years is sufficient for the near-surface variables to reach equilibrium (Lawston et al. 2015).

Control (CTRL) and irrigated (IRR) land-only simulations are completed, in which the only difference is that irrigation is enabled in the IRR run. Irrigation is simulated via a sprinkler parameterization that has been used extensively in previous studies, including a robust evaluation of the triggering and thresholds (Lawston et al. 2017). The sprinkler irrigation algorithm is used in this study as sprinkler systems are the most common irrigation method in this region [National Agricultural Statistics Survey (NASS) 2014]. The sprinkler scheme applies irrigation water as precipitation in the morning when the soil moisture availability drops below $50 \%$ of field capacity (Ozdogan et al. 2010). An irrigation intensity (i.e., spatial frequency) dataset is required to determine the location of irrigation and to scale the amount of water applied to a grid cell in the event that it is not $100 \%$ irrigated. In this study, we use the Global Rainfed and Irrigation Paddy Cropland (GRIPC; Salmon et al. 2015) irrigation intensity dataset. This highspatial-resolution (aggregated to $1 \mathrm{~km}$ ) dataset is derived from a combination of sources, including remote sensing, climate data, and crop inventories.

\subsubsection{Experimental design}

Three 2-day case studies were chosen from the month of July 2015, for which CTRL and IRR coupled LIS-WRF runs were completed. The summer of 2015 featured prolonged dryness and above-average heat. Abnormally dry conditions in June worsened to severe drought in July 2015, according to the U.S. Drought Monitor (Svoboda et al. 2002). The average July high temperature for TriCities Airport in Pasco, Washington, is $32.94^{\circ} \mathrm{C}\left(91.3^{\circ} \mathrm{F}\right)$, based on temperature records from 1981 to 2010 (NCEI 2019), but July 2015 marked 12 days over $37.8^{\circ} \mathrm{C}$ $\left(100^{\circ} \mathrm{F}\right)$, the highest topping out at $42^{\circ} \mathrm{C}\left(108^{\circ} \mathrm{F}\right.$; Weather Underground 2019$)$. The hot and dry weather experienced in 2015 represents the ideal conditions for irrigation application. The selected cases studies, 1-3 July, 16-18 July, and 23-25 July, are rain-free days that feature different wind flow patterns and represent a range of irrigation requirements (Figure S2). The case study of 1-3 July featured high rates $\left(\sim 10 \mathrm{~mm} \mathrm{day}^{-1}\right)$ of irrigation in the northern CBP and little irrigation applied near the Oregon border, while the other case studies showed more widespread irrigation. Rain-free conditions persisted throughout the month, leading to consistent irrigation triggering and greater soil moisture differences between the IRR and CTRL simulations in the 16-18 July and 23-25 July cases (as shown in Figure S3). Overall, irrigation increases the top-layer soil moisture by anywhere from $30 \%$ (i.e., 1-3 July) to as much as $70 \%$ in some grid cells (i.e., 23-25 July).

The LIS-WRF simulations are run for a total of $54 \mathrm{~h}$ per case study. As the focus of this work is on daytime maximum temperatures and boundary layer development, the analysis is concentrated on the daytime hours. The 54-h total run time results in two diurnal cycles per case study, for a total of six daytime periods. Model output from the second domain at $3-\mathrm{km}$ resolution is analyzed for the study area (defined in Figure 1). 
Earth Interactions • Volume 24 (2020) • Paper No. 1 • Page 9

\section{Results}

\subsection{Historical climate results}

The locations of the seven GHCN stations are shown in Figure 2a along with present day map of areas equipped for irrigation (Salmon et al. 2015) and colored lines that indicate county boundaries. The county colors correspond to Figure $2 \mathrm{~b}$, which presents the irrigation acreage from 1890 to 2012, from the USDA Census of Agriculture for the seven most heavily irrigated counties in Washington. The CBP boundaries (Figure 1) span Grant, Franklin, and Adams Counties. Considerable increases in irrigation extent are apparent in these counties in the 1950s following the completion of the CBP infrastructure. In comparison, the other counties display modest and varying trends in irrigation acreage as a result of much smaller, localscale irrigation project development.

Figure 3 shows histograms of JJA daily TMAX values for the pre-CBP and postCBP periods. At five of the seven sites, the distribution noticeably shifts toward cooler temperatures, and the mean is significantly different at the $99 \%$ confidence level, using a Student's $t$ test. The two sites farthest from irrigation, Dayton and Waterville, show nonsignificant cooling and significant warming, respectively. The number of extreme heat days, defined as those days exceeding the 90th percentile for the period of record (Martinez-Austria and Bandala 2017), is also calculated for each station and provided in Table 1. Waterville experiences a 5.3\% increase in extreme heat days, while Odessa, Ellensburg, and Ritzville show a less than $4 \%$ decrease in the number of extreme heat days. Kennewick and Dayton, despite experiencing reduced average JJA TMAX, feature a small increase in the number of extreme heat days.

Figure 4 shows the JJA average TMAX at each GHCN site for each year from 1908 to 2002 with trendlines highlighting the pre- and post-CBP expansion periods. A regionwide cool period in the midcentury (i.e., 1940-50) due to natural climate variability is apparent to varying degrees at each of the stations, with the higher elevation stations (Waterville and Wilbur) experiencing greater cooling. When comparing the pre- and post-CBP periods, Odessa, Wilbur, and Ritzville display the most notable reduction in the post-CBP temperature mean. Odessa, the closest station downwind of the CBP, shows a cooling trend of $-0.05^{\circ} \mathrm{C} \mathrm{yr}^{-1}$ that corresponds to an increasing irrigation trend of about 6000 acres $^{-1} r^{-1}$ (Figure 2c). Waterville and Dayton show warming and nonsignificant cooling, respectively, of the mean maximum temperature in the post-CBP period.

Figures 5a and 6a present the Northwest U.S. (i.e., Washington, Oregon, Idaho) temperature anomalies adapted from Kunkel et al. (2013, their Figure 4). These anomalies were calculated by Kunkel et al. using NOAA'S NCDC temperature dataset with a reference period of 1901-60. The temperature dataset includes the NWS Cooperative Observer Network (COOP) observations as well as a 5-kmresolution gridded, bias-corrected monthly station dataset based on the GHCN observations, now known as nCLIMDIV dataset (Vose et al. 2014). These anomalies provide perspective on the regionwide temperature trends for the periods of interest, allowing us to understand the local temperature changes in context of the background regional climate.

Figure 5a shows an increasing trend in Northwest U.S. DJF temperature anomalies from 1895 to 2011. In particular, the pre-CBP average anomaly is 
(a)

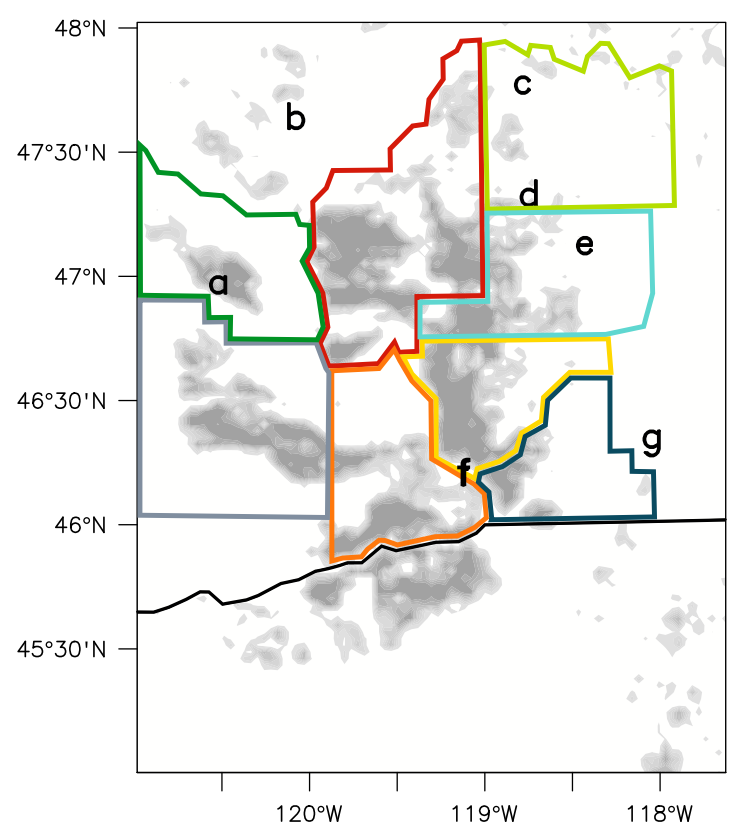

(b)

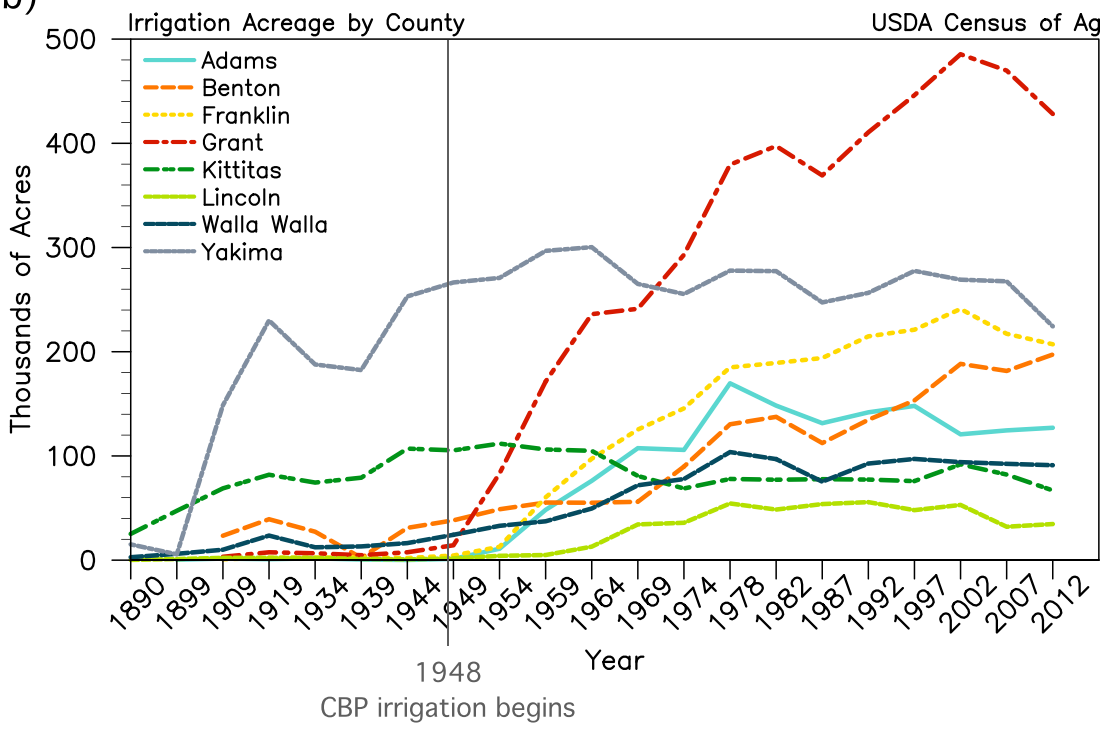

Figure 2. (a) Map of the greater CBP region where gray shading shows present-day irrigation extent (i.e., areas equipped for irrigation) and counties with the greatest irrigation acreage are outlined. (b) Irrigation acreage through time as reported in the USDA Census of Agriculture; colors correspond to counties outlined in (a).

$-0.3^{\circ} \mathrm{C}$, while the post-CBP anomaly is $0.7^{\circ} \mathrm{C}$, indicating that the regional climate in the post-CBP 30-yr period was on average warmer than the pre-CBP period. The analysis of average DJF TMAX at each of the GHCN sites is consistent with the regional climate anomalies, showing warmer average temperatures in the 
(a)

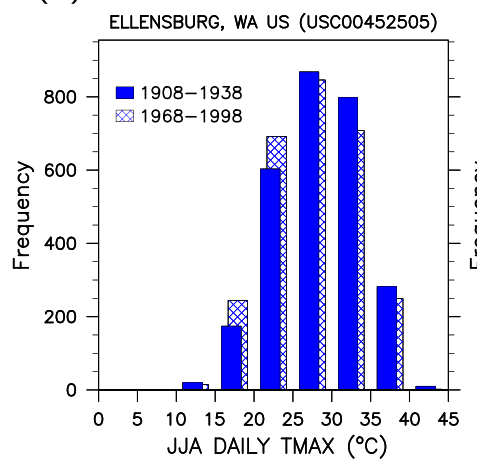

(d)

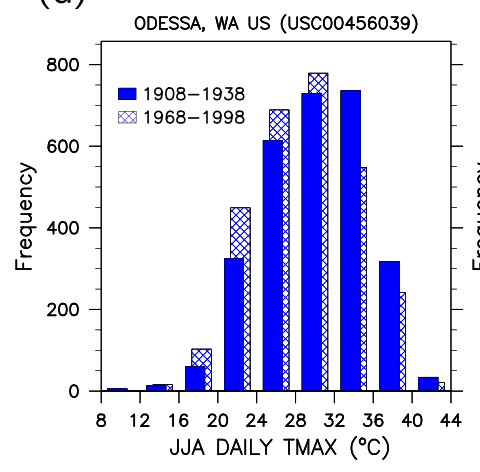

(b)

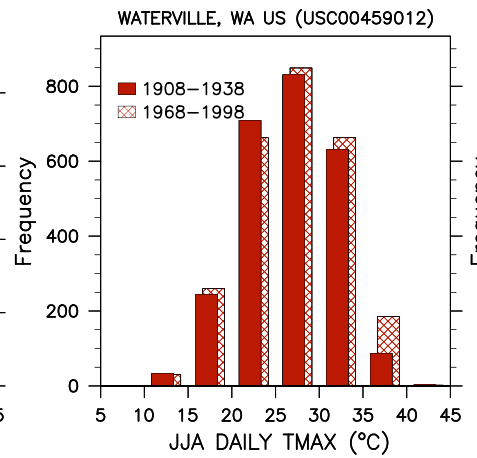

(e)

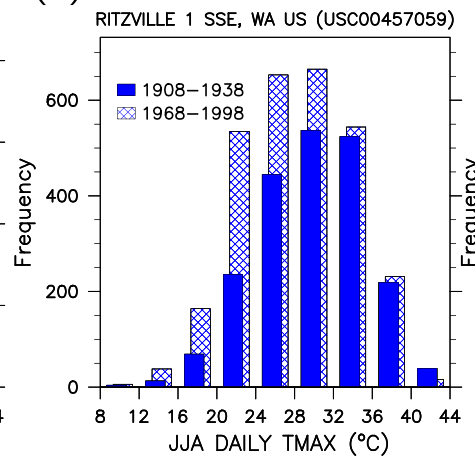

(c)

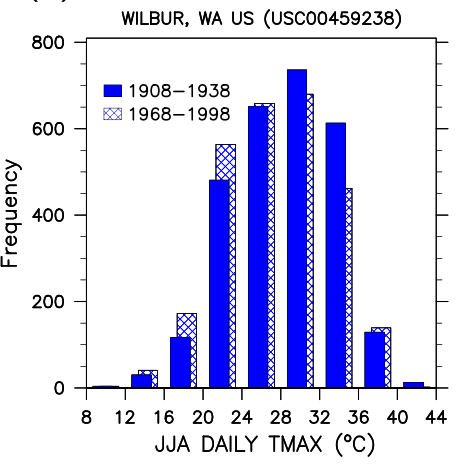

(f)

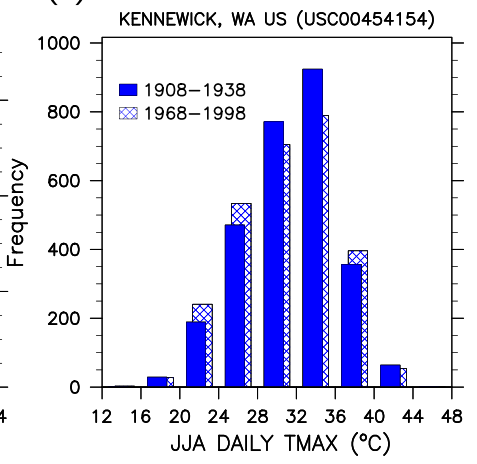

(g)

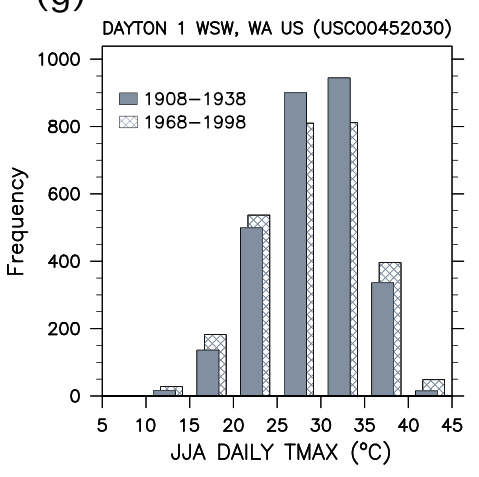

Figure 3. Histograms showing the distribution of June-August (JJA) daily maximum temperatures for the 30-yr periods of 1908-38 (solid) and 1968-98 (hatched) for the seven GHCN sites in Washington: (a) Ellensburg, (b) Waterville, (c) Wilbur, (d) Odessa, (e) Ritzville, (f) Kennewick, and (g) Dayton. Blue (red) coloring denotes that the 1968-98 distribution is significantly cooler (warmer) than the 1908-38 distribution at the $99 \%$ confidence level. 
Earth Interactions - Volume 24 (2020) - Paper No. 1 • Page 12

Table 1. Table of JJA means $\left({ }^{\circ} \mathrm{C}\right)$ and heat extremes for the $\mathrm{GHCN}$ stations. An extreme heat day is defined as a day in which the temperature exceeds the 90th percentile of all JJA extremes in the period of record. An asterisk denotes statistical significance at the $99 \%$ confidence interval.

\begin{tabular}{|c|c|c|c|c|c|c|}
\hline & \multicolumn{3}{|c|}{ JJA mean $\left({ }^{\circ} \mathrm{C}\right)$} & \multicolumn{3}{|c|}{ No. of extreme heat days } \\
\hline & Pre & Post & Difference & Pre & Post & Difference \\
\hline Ellensburg & 28.0 & 27.2 & $-0.76^{*}$ & $357(13 \%)$ & $310(11.2 \%)$ & $-1.7 \%$ \\
\hline Waterville & 26.3 & 26.8 & $0.51 *$ & $224(8.8 \%)$ & $376(14.2 \%)$ & $5.3 \%$ \\
\hline Wilbur & 28.3 & 27.4 & $-0.87 *$ & $364(13.1 \%)$ & $325(11.9 \%)$ & $-1.2 \%$ \\
\hline Odessa & 29.9 & 28.8 & $-1.12 *$ & $352(12.4 \%)$ & $262(9.2 \%)$ & $-3.2 \%$ \\
\hline Ritzville & 29.8 & 28.1 & $-1.67 *$ & $258(12.4 \%)$ & $247(8.7 \%)$ & $-3.7 \%$ \\
\hline Kennewick & 31.3 & 30.9 & $-0.37 *$ & $266(9.5 \%)$ & $305(11.1 \%)$ & $1.6 \%$ \\
\hline Dayton & 28.7 & 28.6 & -0.07 & $284(10 \%)$ & $363(12.9 \%)$ & $2.9 \%$ \\
\hline
\end{tabular}

post-CBP period. Five of the seven sites show statistically significant warming of the mean at the $99 \%$ confidence level (Figure 5b). In DJF, when there is no irrigation, the local temperature signal at the GHCN sites is consistent with the regional temperature signal.

Figure 6 presents the same analysis but for JJA mean TMAX. The regional temperature anomalies from NOAA show a slight warming in the post-CBP period. However, five of the six GHCN sites show statistically significant cooling in the average JJA TMAX for the post-CBP period. Figure $6 \mathrm{c}$ shows wind roses derived from all available years of JJA AgriMet data at seven sites in the study area. These sites are different from the GHCN locations, but they are in close enough proximity to provide a prevailing wind flow pattern for the region. The three GHCN sites that exhibit the greatest cooling, Odessa, Ritzville, and Wilbur, have a prevailing JJA wind direction from the southwest (Figure 6c) and are therefore most often downwind of CBP irrigation. The Ellensburg and Kennewick sites also show statistically significant cooling. Although these sites are not downwind of the CBP irrigation, they are in close proximity to other irrigation projects, not analyzed in this study. The Waterville site, upwind of CBP irrigation and not within close proximity to other irrigation projects, shows a statistically significant warming more in line with the regional temperature anomalies. At Dayton, a slight but nonsignificant cooling is present.

\subsection{Satellite remote sensing results}

The climate data analysis indicates a significant local impact of irrigation on climate that corresponds with the implementation of irrigation over the region. Next, we use satellite remote sensing datasets to better understand the current extent of irrigation impacts to SM and LST. The SMAP data record begins in April 2015. As a result, we show results for 2016, as it is the first full year in which there are both SMAP SM and MODIS Terra LST data available.

Figure 7 a presents the average daily daytime ( 1200 local time) MODIS LST for the month of July for the study region. Only data that have "good" quality flags are used in the average LST calculation. The bright green colors at the center of the valley show that the LST in the irrigated area is on average about $20^{\circ} \mathrm{C}$ cooler than the surrounding land. To identify whether these differences exist outside of July, 
Earth Interactions - Volume 24 (2020) • Paper No. 1 • Page 13
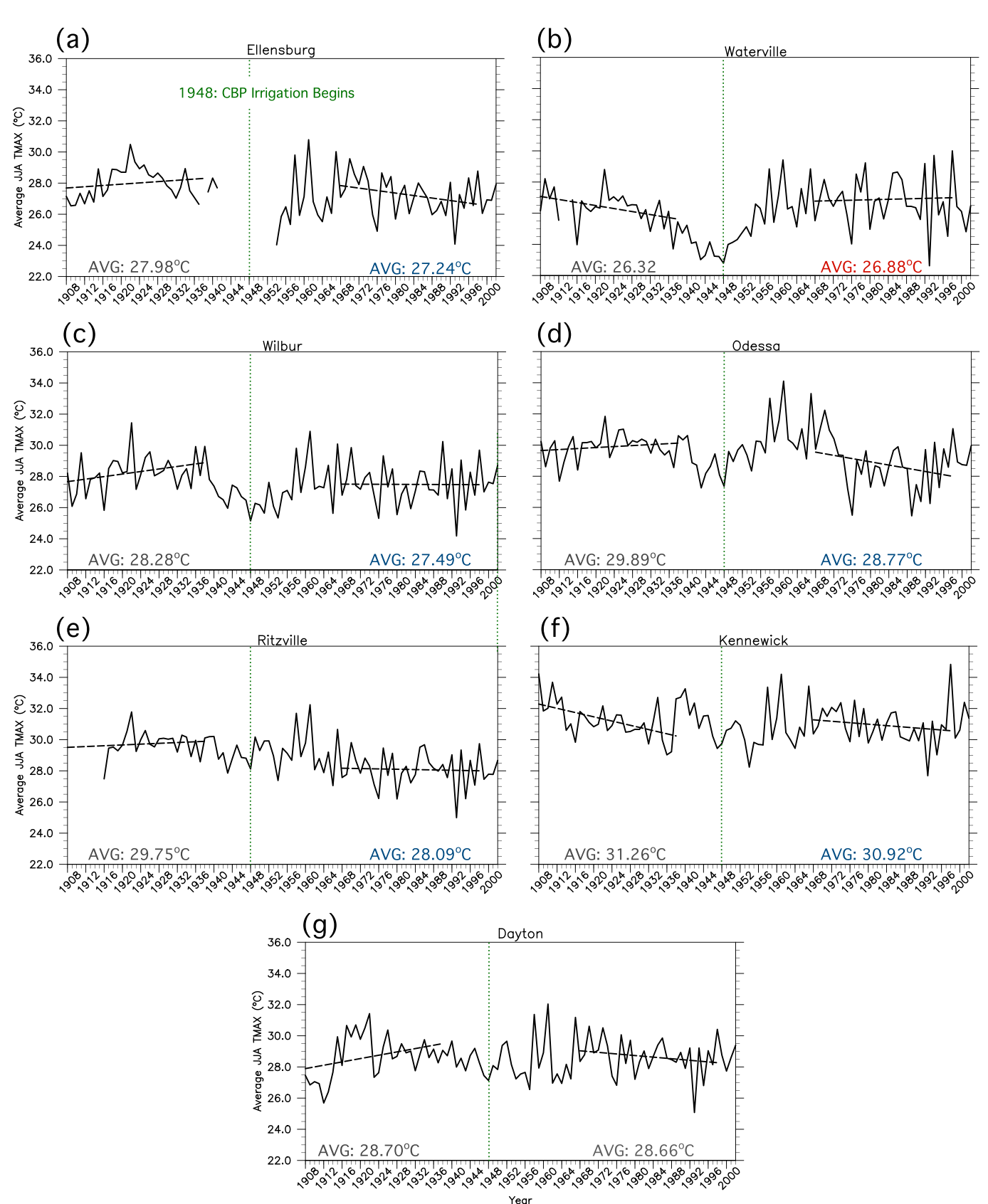

Figure 4. Time series of JJA-average TMAX for the seven GHCN sites with trendlines and averages for the 1908-38 and 1968-98 time periods. Blue (red) coloring of averages indicates a statistically significant cooling (warming) at the $99 \%$ confidence level.

the LST observations are plotted for a full year (Figure 7b) at two points about $25 \mathrm{~km}$ apart, indicated by the circle and triangle in Figure $7 \mathrm{a}$, and identified as irrigated and nonirrigated, respectively. The rainy season is typically from late October through March, bringing with it cloud cover that prohibits LST 
Earth Interactions - Volume 24 (2020) • Paper No. 1 • Page 14

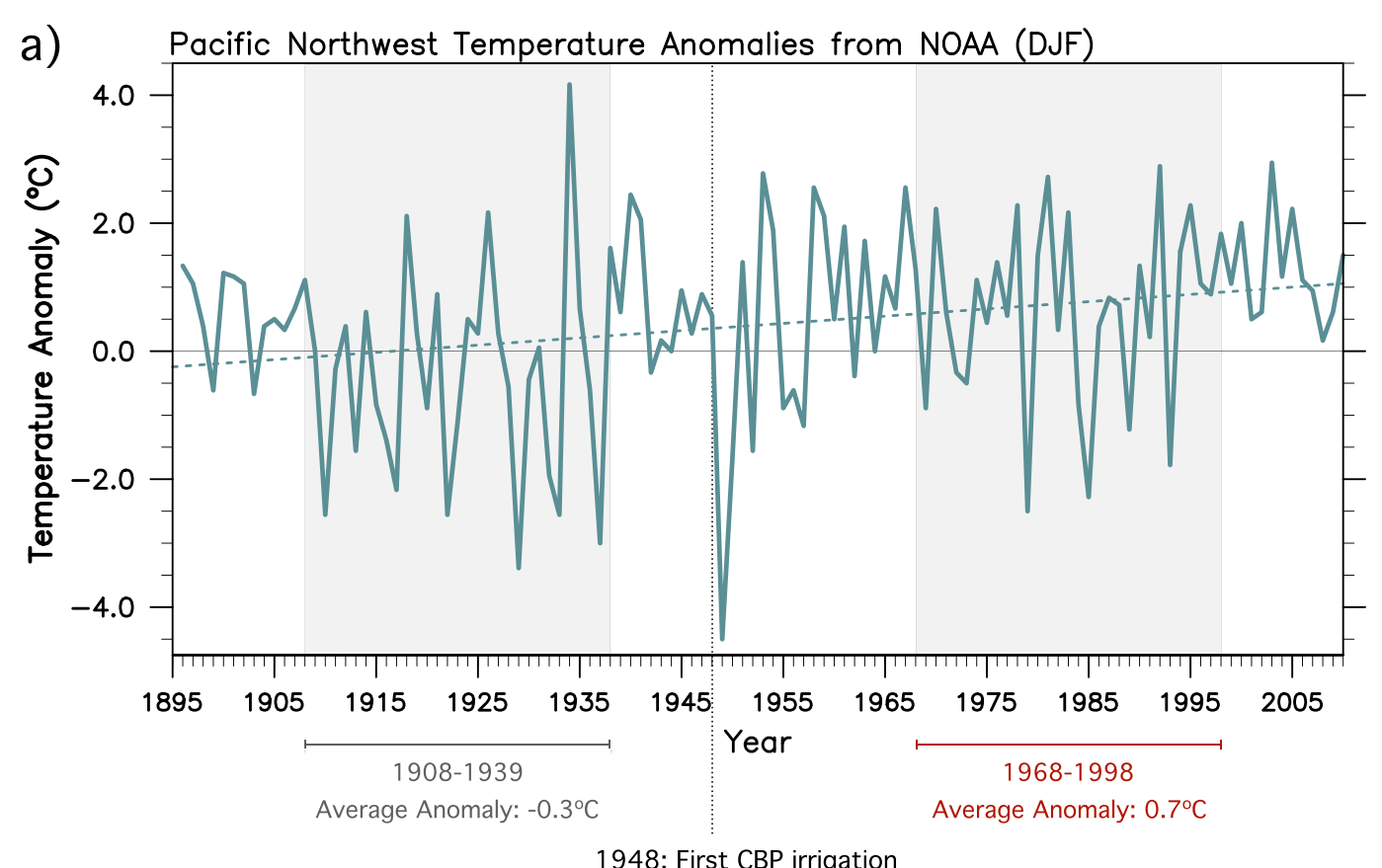

b)

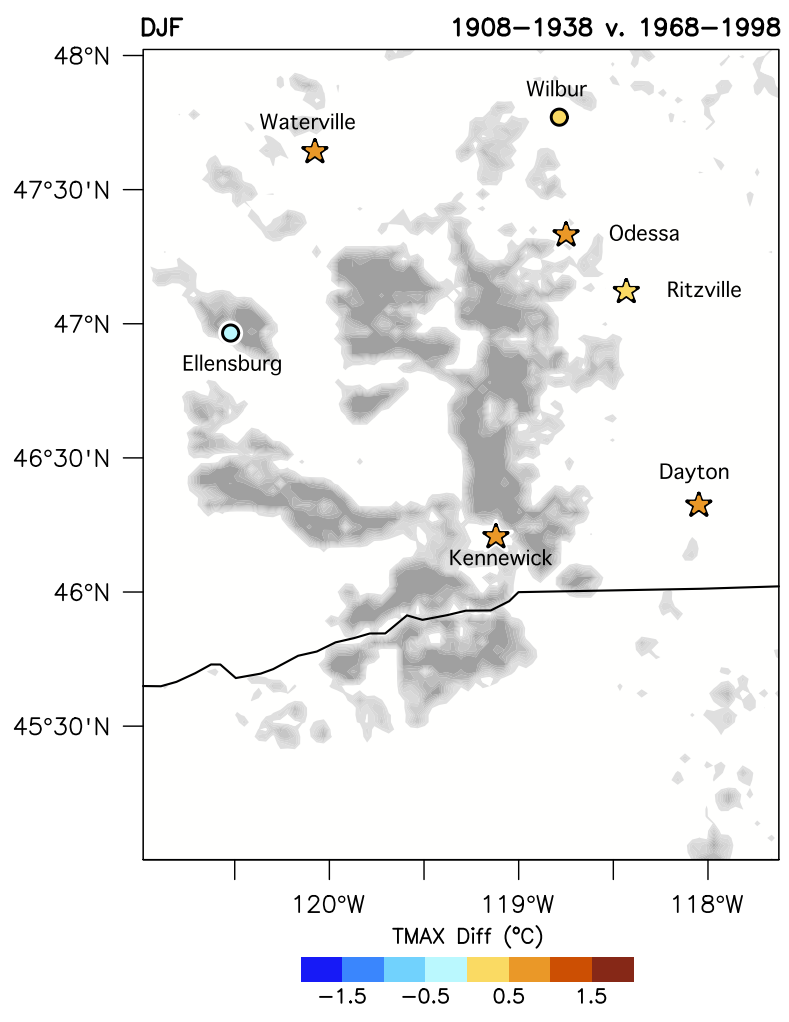

Figure 5. (a) Time series of Pacific Northwest winter (DJF) temperature anomalies adapted from the NOAA Climate report (reproduced from Kunkel et al. 2013, Figure 4). (b) Difference in average DJF TMAX between 1908 and 
Earth Interactions - Volume 24 (2020) • Paper No. 1 • Page 15

1938 and 1968 and 1998 at each of the GHCN sites. Warmer (cooler) markers show the 1968-98 average was warmer (cooler) than 1908-38. Stars denote statistical significance at the $99 \%$ confidence level; circles denote differences that are not statistically significant. Gray shading indicates present-day irrigation extent.

observations and results in significant data gaps during these months. However, even despite the data availability, it is clear from the yearly time series that the irrigated and nonirrigated sites exhibit similar temperatures outside of the growing season and that the temperatures diverge once irrigation begins in April, hitting their maximum differences during the highest radiation input in June and July.

It should be noted that there is an elevation difference between the two sites; the nonirrigated site sits at about $100 \mathrm{~m}$ higher than its counterpart (i.e., 260 vs. $371 \mathrm{~m}$, respectively). However, this elevation difference should serve to cool the nonirrigated site, mitigating the difference between irrigated and nonirrigated and therefore not influencing the conclusions.

The same type of spatial map and time series analysis is completed for the SMAP soil moisture observations and is shown in Figures 7c and 7d. The SMAP soil moisture is a much coarser resolution than MODIS LST (36 vs. $1 \mathrm{~km}$, respectively) and therefore the detailed irrigation features are not quite as striking as in the MODIS LST. However, the irrigated area at the center of the valley is still clear as it exhibits soil moisture values that are on average about 0.05$0.07 \mathrm{~cm}^{3} \mathrm{~cm}^{-3}$ wetter than the surrounding area. As this region is climatologically dry, this difference is nontrivial, as it represents about $18 \%-25 \%$ of the maximum range (i.e., $\sim 0.27 \mathrm{~cm}^{3} \mathrm{~cm}^{-3}$ ). The full-year time series shows that the irrigated and nonirrigated points again have similar values outside of the growing season, but they diverge in April when irrigation water becomes available. Taken together, the LST and SMAP results show that irrigation makes the soil wetter and reduces the land surface temperature considerably. Based on the dramatic difference in LST, it is hypothesized that at least some of this heterogeneity in temperature is transferred to the lower atmosphere. If so, it is also possible that irrigation impacts are not confined to the individual fields that are irrigated, but rather that these activities can affect adjacent and downwind regions, leading to the temperature reduction shown in observations at the downwind GHCN sites. This hypothesis will be tested next using the modeling framework described in section 3.3.2.

\subsection{Regional modeling results}

To investigate these 3D processes, we now focus on the wind flow patterns, potential downwind persistence of irrigation effects, and impacts at each of the GHCN sites by analyzing the results of the LIS-WRF simulations. Figure 8 shows the difference (IRR-CTRL) in simulated TMAX resulting from the irrigation on each case study day. Immediately apparent are two features: 1) there is considerable cooling resulting from simulated irrigation $\left(>2{ }^{\circ} \mathrm{C}\right.$ in some places), and 2 ) there are very different orientations to the cooling patterns depending on the case study. On 1-2 July, light and variable winds cause the greatest cooling of all case study days directly over the irrigation and also limit the spread of the irrigation 
a)

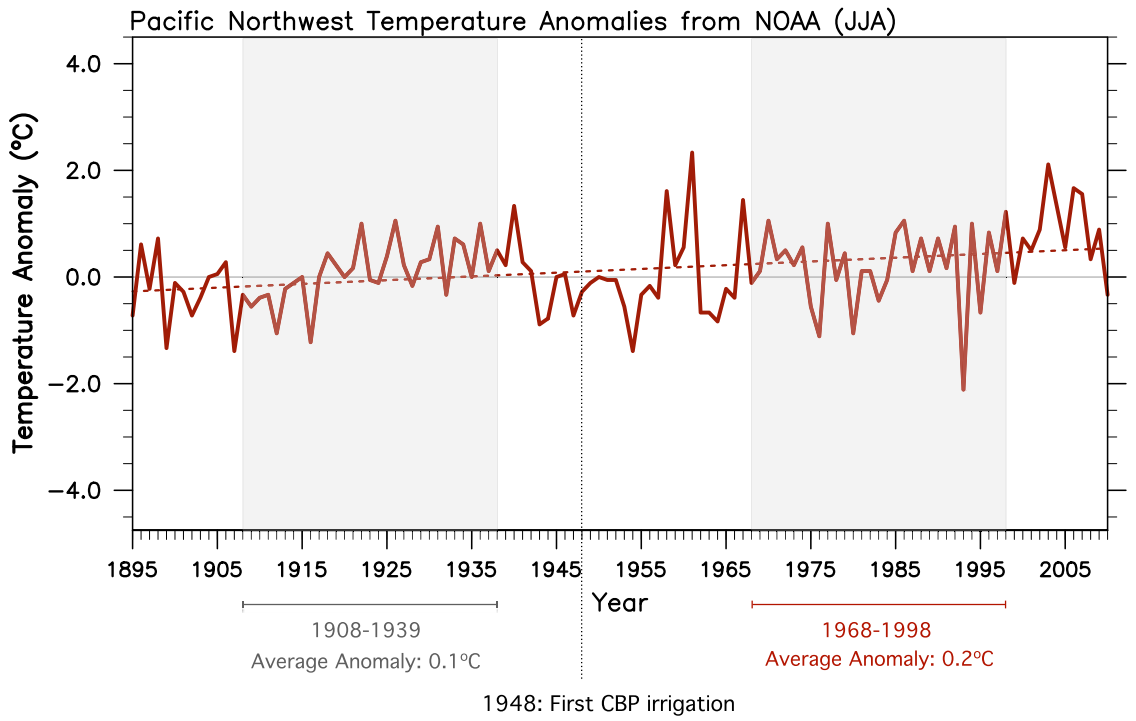

b)

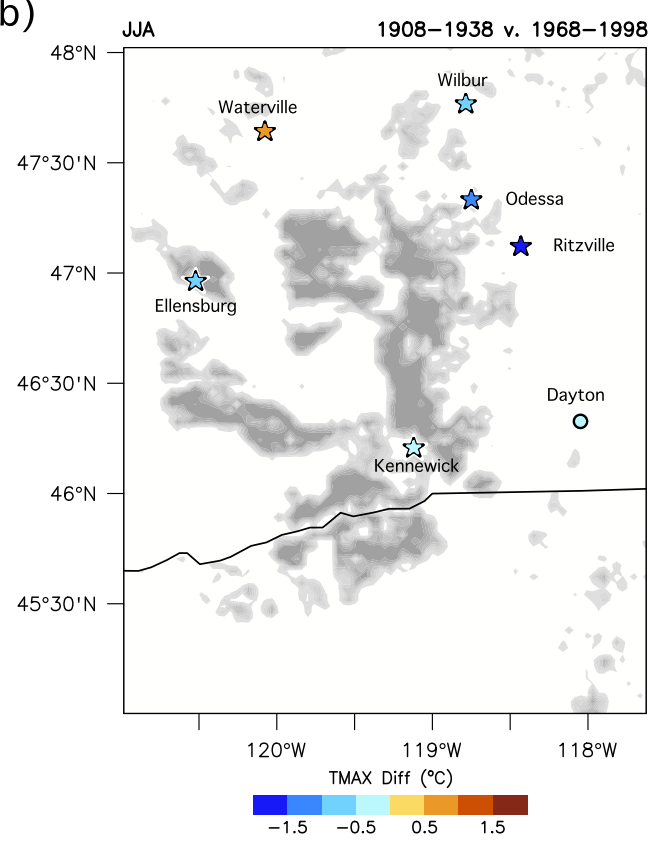

c)

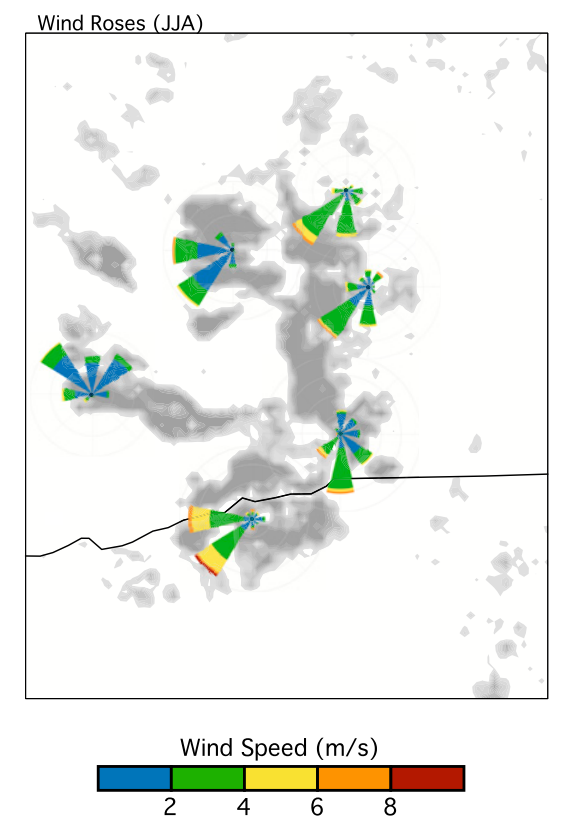

Figure 6. (a),(b) As in Figure 5, but for summertime anomalies (JJA). (c) Wind roses generated using data from the AgriMet weather station network for JJA. Wind directions are binned into eight classes: N $\left(326.25^{\circ}-11.25^{\circ}\right), \mathrm{NE}$ $\left(11.25^{\circ}-56.25^{\circ}\right), \mathrm{E}\left(56.25^{\circ}-101.25^{\circ}\right)$, SE $\left(101.25^{\circ}-146.25^{\circ}\right), \mathrm{S}\left(146.25^{\circ}-191.25^{\circ}\right)$, SW $\left(191.25^{\circ}-236.25^{\circ}\right)$, W $\left(236.25^{\circ}-281.25^{\circ}\right)$, and NW $\left(281.25^{\circ}-326.25^{\circ}\right)$.

cooling to only those areas within $5-10 \mathrm{~km}$ of the irrigated region. The $16-18 \mathrm{July}$ case exhibited slightly stronger westerly to northwesterly winds, which transport the irrigation-cooled air farther on 16 July than 1-3 July. The 23-25 July case featured strong southwesterly winds that allow the irrigation-cooled air to travel up 
(a)

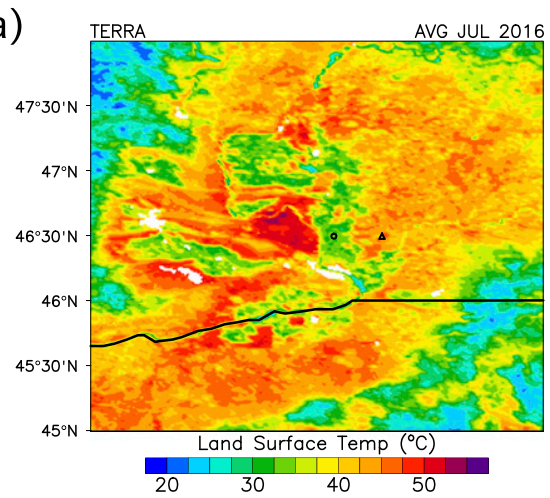

(c)

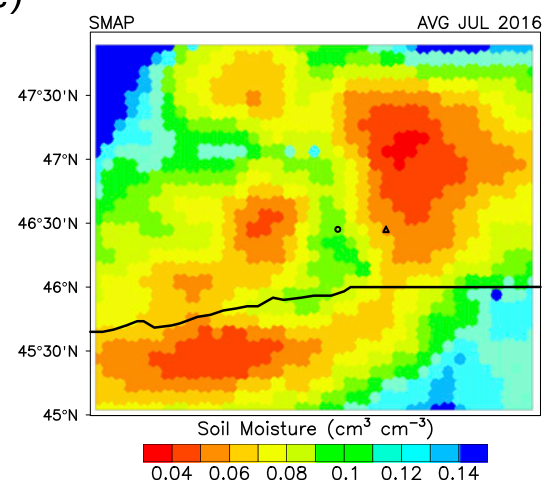

(b)

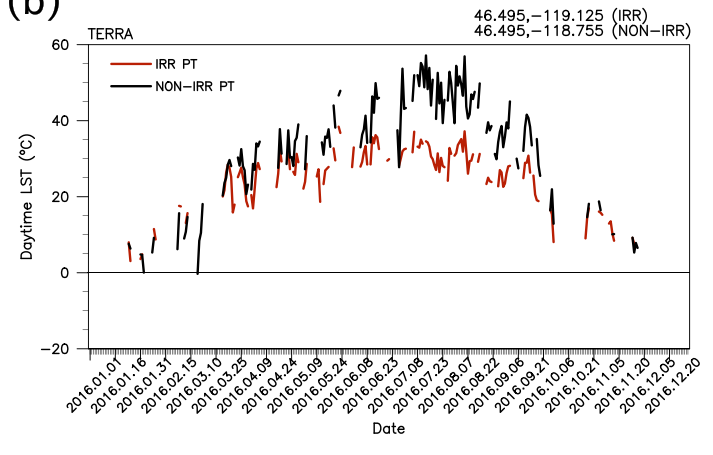

(d)

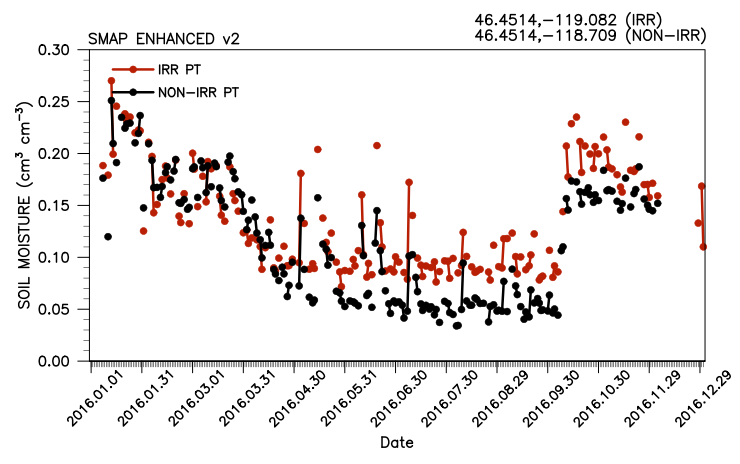

Figure 7. MODIS Terra (a) average daytime ( 1200 local time) LST for July 2016, and (b) time series of LST at an irrigated (circle) and a nonirrigated (triangle) site for full year 2016. SMAP Enhanced Level 3 (c) average SM for July 2016, and (d) time series of SM at irrigated and nonirrigated point locations over full year 2016.

to $40 \mathrm{~km}$, the greatest distance of all the case studies. In all cases, the greatest daily cooling occurs directly over the irrigated area.

The prevailing JJA wind direction derived from the AgriMet observations (Figure 6c) suggests that the 23-25 July case is the most representative summertime wind flow pattern for this region. This is particularly revealing because Figure 8 agrees with the historical climate analysis results in that the irrigation impacts reach all of the sites that exhibited JJATMAX mean cooling in the pre- versus postCBP analyses. Waterville, which showed warming in the historical analysis, is not in the sphere of influence of irrigation in any of the three case study wind regimes.

As the 23-25 July case is the most representative of the prevailing JJA wind patterns, we present more detailed analysis of the model results for these dates. Figure 9 shows the temperature and humidity difference vertically through the atmosphere along a transect through a heavily irrigated part of the CBP. Also shown is the corresponding soil moisture difference along this same transect. Increased soil moisture from the irrigation parameterization results in more energy being partitioned into latent heating (increases by $70-110 \mathrm{~W} \mathrm{~m}^{-2}$; Figure S4), which results in increased humidity throughout the depth of, but capped by, the 


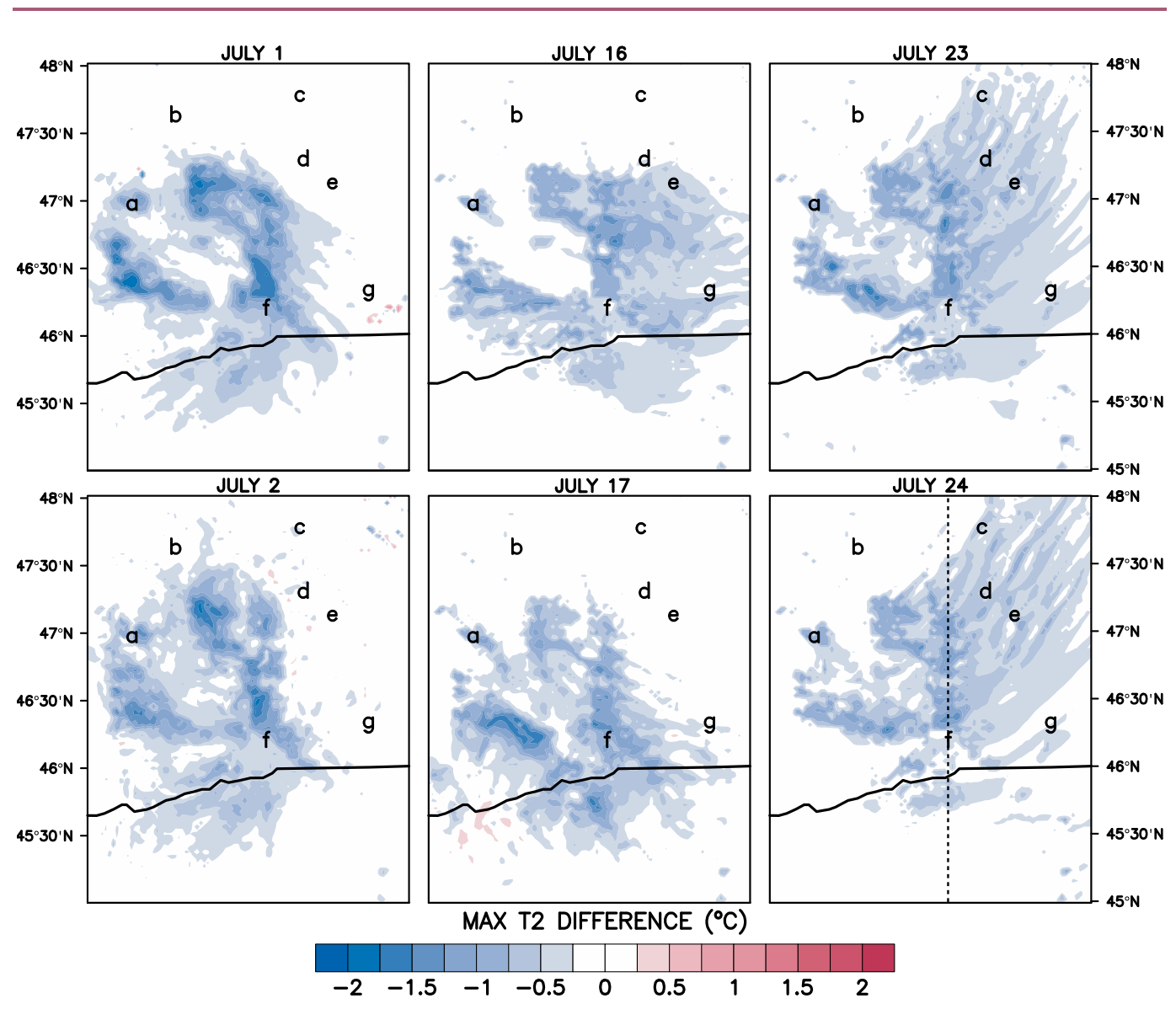

Figure 8. Daily TMAX difference between irrigated and nonirrigated NU-WRF Model simulations for each case study day. Letters denote the locations of each GHCN site: (a) Ellensburg, (b) Waterville, (c) Wilbur, (d) Odessa, (e) Ritzville, (f) Kennewick, and (g) Dayton. (bottom right) Dashed line indicates the location of the cross section shown in Figure 9.

PBL. The PBL height is reduced in the irrigated simulations, resulting in the dipole of cool over warm (temperature) and dry over moist (humidity) features in the cross section. The drier and warmer areas indicate the height to which the PBL grew in the CTRL run.

The advection of the irrigation-cooled and moistened air downstream limits a negative feedback on evaporative demand that could otherwise result. For example, the wetter soil increases latent heat flux and 2-m humidity, decreases the boundary layer height, and reduces entrainment, creating a moister PBL. This situation could inhibit evaporative demand and reduce latent heat flux (e.g., negative feedback), but the advection of the moister air downwind helps to maintain the irrigation effect.

The town of Odessa, Washington, is unique in that it hosts both GHCN and AgriMet sites, meaning that there are historical climate data as analyzed in section 4.1 and more recent weather data with a higher temporal sampling rate. Figure 10 
Earth Interactions - Volume 24 (2020) • Paper No. 1 • Page 19

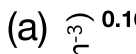

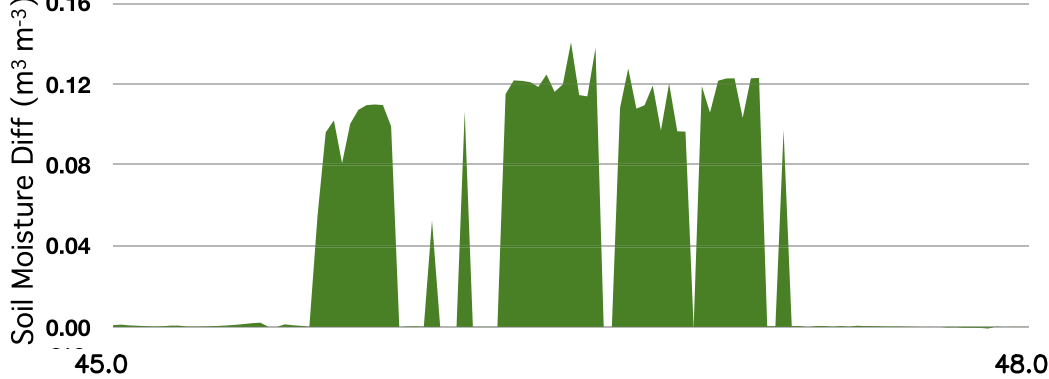

(b)

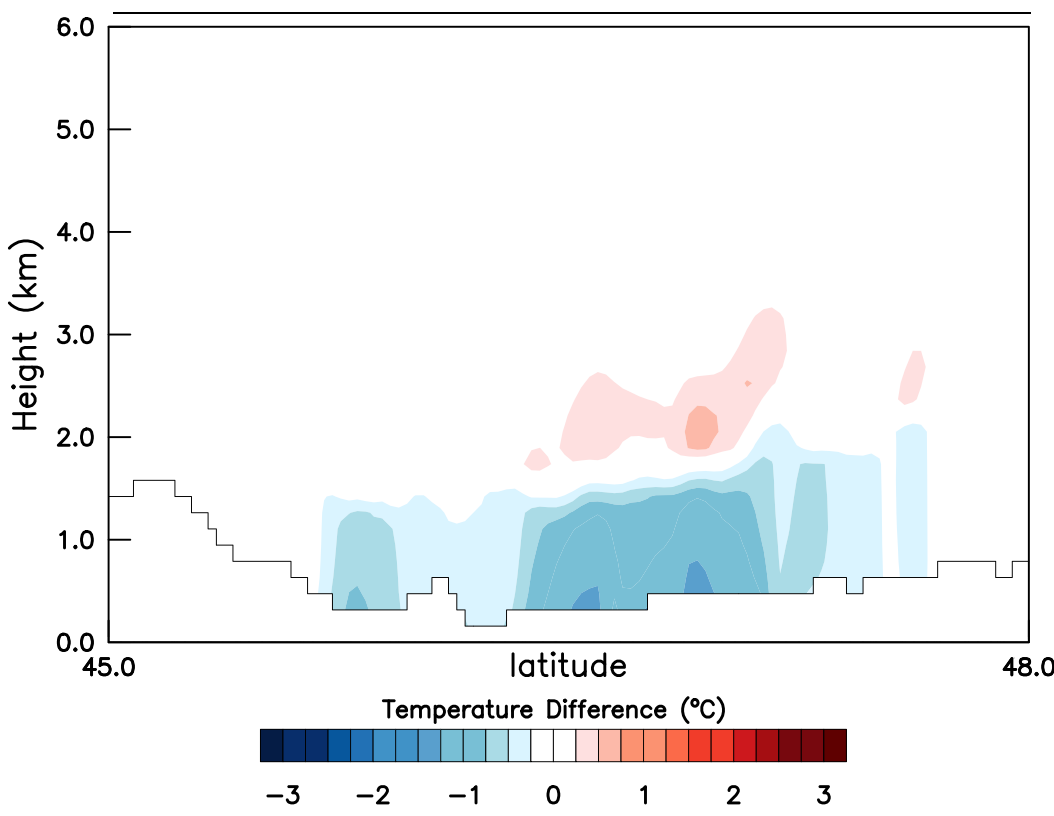

(c)

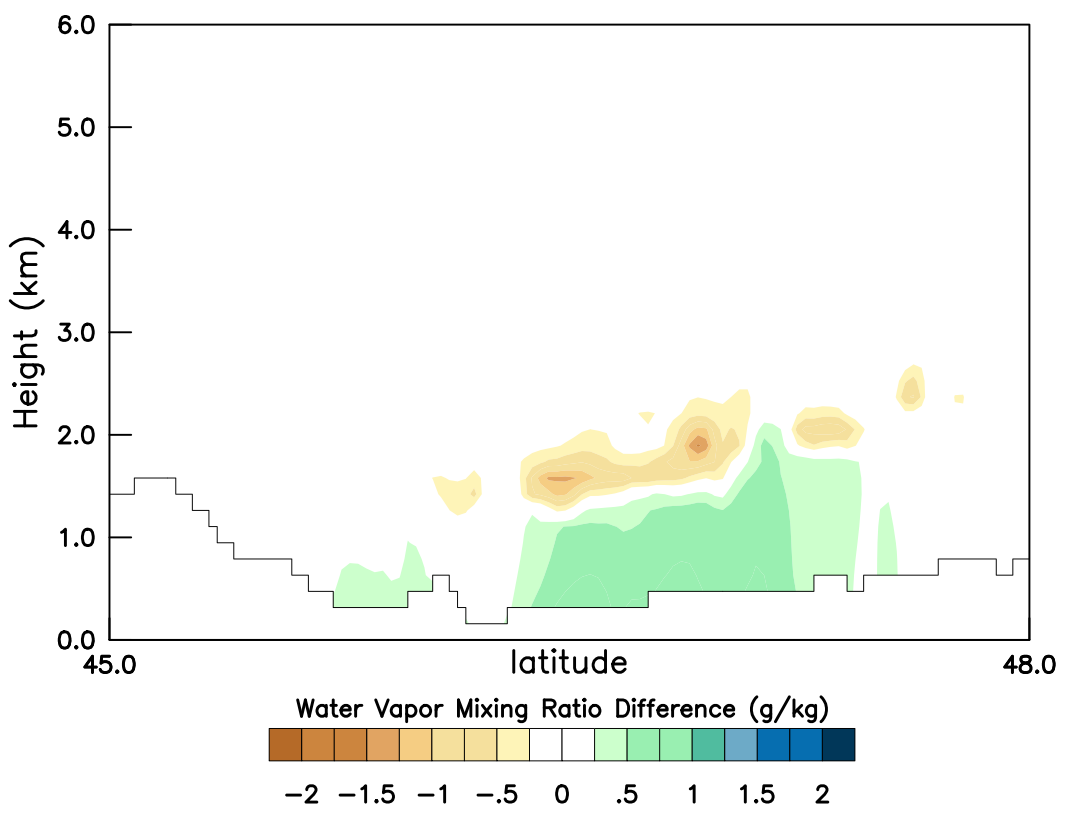


Earth Interactions - Volume 24 (2020) • Paper No. 1 • Page 20

Figure 9. (a) Bar chart of the soil moisture difference between the irrigated and nonirrigated runs at midday (13:00 local time; PDT) 23 July along a transect shown in the bottom-right panel of Figure 8 (i.e., $45^{\circ}-48^{\circ} \mathrm{N}, 119.1^{\circ} \mathrm{W}$ ). (b),(c) Vertical cross sections at the same time and location as (a) showing the difference through the lower atmosphere for (b) water vapor mixing ratio and (c) temperature between the irrigated and nonirrigated NU-WRF Model simulations.

presents the diurnal cycle of temperature, humidity (dewpoint temperature), and winds at Odessa in the LIS-WRF simulations as compared to the 15-min AgriMet observations.

In both the CTRL and IRR simulations, the LIS-WRF Model simulations exhibit a warm and dry bias during the daytime hours of 23-24 July. The simulated irrigation mitigates this bias slightly by reducing the temperature and increasing the humidity. Interestingly, for the other two case study days (Figures S5 and S6), the model temperature is very close to the observations and the model humidity is greater than observations. It is only for the case in which there was a southwesterly wind (i.e., from the direction of irrigation) that the model is warmer and drier than what is observed. The wind direction simulated by both model simulations at Odessa is consistent with observations, but the wind speed particularly at midday is stronger (i.e., about $2 \mathrm{~m} \mathrm{~s}^{-1}$ ) than observed. It is unlikely that this high wind bias impacts the conclusions as the simulated irrigation cooling extends beyond the GHCN station locations, implying a slightly lighter wind would not prevent the cooling effect from reaching these locations.

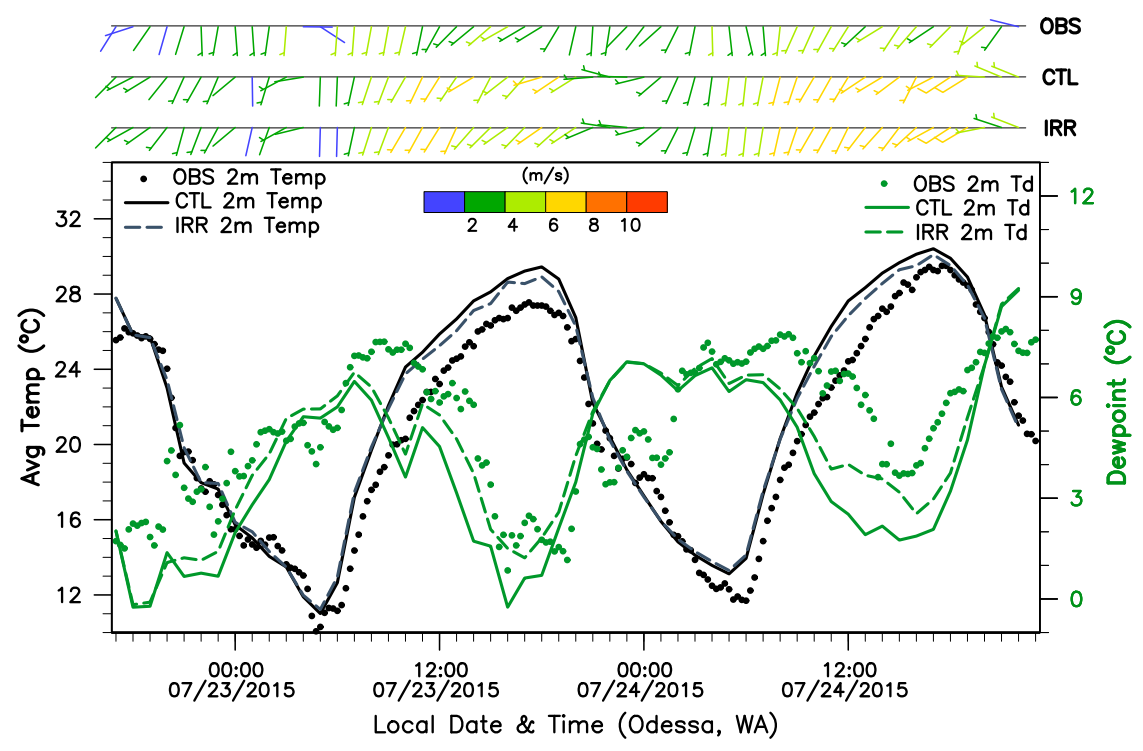

Figure 10. Time series of temperature, dewpoint, and wind speed and direction for the control and irrigated NU-WRF Model simulations and AgriMet observations at Odessa, WA, for the 23-25 Jul case study. 
Earth Interactions - Volume 24 (2020) • Paper No. 1 - Page 21

\section{Discussion}

The historical GHCN analysis is limited in that there are only a small number of stations available that have sufficiently long records and few substantial data gaps. More stations, particularly within the irrigated CBP region itself, would allow for a more robust analysis such as that from Lobell and Bonfils (2008), who used a linear regression method to relate irrigated cooling to trends in irrigated acreage. In addition, some information exists about GHCN station relocation, but it is sparse and imprecise, particularly in the earliest periods of the data record. However, a significant station relocation would produce systematic changes impacting DJF and JJA temperatures in the same way. The fact that DJF mean temperatures warmed, but that JJA mean temperatures cooled at the same stations gives confidence that the JJA cooling is not caused by station relocation. Overall, the consistency of the historical analysis with the model results and the complementary information gained from the remote sensing analysis together suggest that the GHCN conclusions are reasonable, despite the small number of stations.

It should be noted that the methodology of Lobell and Bonfils (2008) is considered an improvement upon previous observational analysis methods, as their approach avoids complications of pairwise comparisons (e.g., direct comparison of "irrigated" vs. "nonirrigated" sites) that can confound signal with noise from station relocation or concurrent climate changes. We do not use this method for two reasons. First, as mentioned, the sparseness of GHCN sites in the vicinity of the CBP, particularly in the most heavily irrigated areas prohibits the linear regression approach. Second, the Lobell and Bonfils (2008) methodology assumes all impacts are local, ignoring the potential influence of advection from nearby irrigated areas. In this work, we are particularly interested in the downstream (i.e., advected) influence of irrigation. We circumvent the pitfalls raised by avoiding pairwise comparisons and instead assessing the results in the context of the prevailing wind and regional climate.

The large LST difference between irrigated and nonirrigated areas given by the remote sensing results is due to a combination of direct (i.e., increased soil moisture and ET via added water) and indirect (i.e., land-cover/vegetation change) effects of irrigation. The majority of nonagricultural acreage in this region is shrubland, owing to the small amount of average annual precipitation (8-10 in., 1 in. $=25.4 \mathrm{~mm}$; Kugler and Woodward 2006), creating a dramatic and unique contrast between the irrigated and nonirrigated regions. The methodology for the LST comparison applied in other regions where irrigated crops are bounded by rainfed versions of the same crop (e.g., irrigated and rainfed corn in Nebraska) or where irrigation exists in proximity to other dense vegetation (e.g., forests) would not exhibit such large LST differences.

The model simulations are subject to a range of inherent uncertainties, including the way in which irrigation is simulated. Although we have confidence in the irrigation scheme and its assumptions stemming from its extensive testing in previous studies (Ozdogan et al. 2010; Lawston et al. 2017), a more sophisticated approach would use a combination of different types of irrigation methods (e.g., drip, flood) rather than sprinkler only. However, the dominant irrigation method for this region is sprinkler, so the conclusions are unlikely to be affected by only using the sprinkler method. Additionally, the model treats all crops as a general crop 
Earth Interactions - Volume 24 (2020) - Paper No. 1 • Page 22

category, but recent work has shown that the extent of the irrigation cooling effect can depend on crop type (Chen et al. 2018). Progress is needed and will likely be made in these areas in the future as the community works toward better representation of irrigation dynamics in weather and climate models.

This work focuses specifically on daily TMAX and understanding the factors that could contribute to changes in temperature. However, irrigation has been posited, and in some cases, shown to impact other atmospheric variables as well, including cloud cover and precipitation (DeAngelis et al. 2010; Wei et al. 2013; de Vrese et al. 2016; Pei et al. 2016; Alter et al. 2015). Although a comprehensive analysis of all boundary layer feedbacks is beyond the scope of this study, we investigated the impact of irrigation on clouds in the model simulations by analyzing the lifting condensation level deficit (LCL deficit; Santanello et al. 2011) and the vertically integrated cloud liquid water (Figures S6 and S7, respectively). The analysis suggested that irrigation increases the potential for convective clouds, but despite the lowering of the LCL over irrigated regions due to increased humidity, the PBL still cannot reach the LCL due to reduced buoyancy. This means that irrigation moves the atmosphere toward a more favorable state for cloud development, but it is not sufficient for triggering new clouds or significantly modifying the few clouds that did develop. As a result, the near-surface air temperature cooling is not amplified by a positive cloud feedback in this case. However, it is highly likely that this result is unique to this time period and region and would differ elsewhere where there is more support for deeper PBL growth, even with a wet surface. Future work is needed to investigate the full range of these impacts in this and other regions.

\section{Conclusions}

This study used local observations, satellite remote sensing, and numerical modeling to 1) explore whether irrigation has historically impacted summer maximum temperatures in the Columbia Plateau, 2) characterize the current extent of irrigation impacts to soil moisture (SM) and land surface temperature (LST), and 3) better understand the downstream extent of irrigation's influence on near-surface temperature, humidity, and boundary layer development. Analysis of historical daily TMAX observations showed that the three GHCN sites downwind of CBP irrigation experienced statistically significant cooling of the mean JJA TMAX by $0.8^{\circ}-1.6^{\circ} \mathrm{C}$ in the post-CBP (1968-98) as compared to pre-CBP expansion (190838 ), opposite the background climate signal. Remote sensing observations of soil moisture and land surface temperatures in more recent years show considerably wetter soil ( $\sim 18 \%-25 \%)$ and cooler land surface temperatures, as much as $20^{\circ} \mathrm{C}$ cooler over the irrigated areas as compared to nearby nonirrigated areas, due to a combination of direct (increased soil moisture and ET) and indirect (land-cover/ vegetation change) effects of irrigation. LIS-WRF Model simulation results support the historical analysis, confirming that under the most common JJA wind flow regime, irrigation cooling can extend as far downwind as, and beyond, the locations of these stations. Taken together, these results suggest that irrigation expansion may have contributed to a reduction in summertime temperatures and heat extremes within and downwind of the Columbia Basin Project, and therefore, support a regional (i.e., beyond local) impact of irrigation in the study area. 
The LIS-WRF Model simulation also enabled a better understanding of the processlevel connections between irrigation, SM changes, and daily summertime weather in the study area via boundary layer processes and feedbacks that link the land surface and atmosphere. The model results showed that the advection of irrigation cooled and moistened air downstream, limits a negative feedback on evaporative demand that could otherwise result, helping to maintain the irrigation effect. These results complement Lawston et al. (2015), which showed that irrigation can reduce both the lifting condensation level and the PBL height over and downwind of irrigated areas.

The dry climate and water use regulations of the Columbia Plateau differentiate it from other irrigated areas in the United States, such as those in the Great Plains. For example, the irrigation season is longer, stretching from April through October, while most irrigation occurs in June through August in Nebraska. This prolonged irrigation season could be a contributing factor to the weather and climate impacts shown here. Future work could compare a region of similar climate to the Columbia Plateau (e.g., the California Central Valley, the Iberian Peninsula), but with different irrigation timing and practices to understand the contribution of the extended irrigation season. Overall, these results underscore the need to consider human water management impacts when analyzing or predicting components of the water and energy cycles, and in particular, highlight the importance of including irrigation in regional weather and climate models.

Acknowledgments. This study was supported by NASA Grant NNH15ZDA001NSUSMAP and the NASA Earth and Space Science Fellowship NNX15AM71H. Resources supporting this work were provided by the NASA High-End Computing (HEC) Program through the NASA Center for Climate Simulation (NCCS) at Goddard Space Flight Center.

\section{References}

Abatzoglou, J. T., D. E. Rupp, and P. W. Mote, 2014: Seasonal climate variability and change in the Pacific Northwest of the United States. J. Climate, 27, 2125-2142, https://doi.org/10.1175/ JCLI-D-13-00218.1.

Adegoke, J. O., R. A. Pielke J. Eastman R. Mahmood, and K. G. Hubbard, 2003: Impact of irrigation on midsummer surface fluxes and temperature under dry synoptic conditions: A regional atmospheric model study of the U.S. high plains. Mon. Wea. Rev., 131, 556-564, https://doi.org/10.1175/1520-0493(2003)131<0556:IOIOMS>2.0.CO;2.

Alter, R. E., Y. Fan, B. R. Lintner, and C. P. Weaver, 2015: Observational evidence that Great Plains irrigation has enhanced summer precipitation intensity and totals in the Midwestern United States. J. Hydrometeor., 1717-1736, https://doi.org/10.1175/JHM-D-14-0115.1.

Barnston, A. G., and P. T. Schickedanz, 1984: The effect of irrigation on warm season precipitation in the southern Great Plains. J. Climate Appl. Meteor, 23, 865-888, https://doi.org/10.1175/ 1520-0450(1984)023<0865:TEOIOW >2.0.CO;2.

CBDL, 2018: Columbia Basin Project. Accessed 1 June 2018, https://www.cbdl.org/about/ columbia-basin-project/.

Chen, F., and J. Dudhia, 2001: Coupling an advanced land surface-hydrology model with the Penn State-NCAR MM5 Modeling System. Part I: Model implementation and sensitivity. Mon. Wea. Rev., 129, 569-585, https://doi.org/10.1175/1520-0493(2001)129<0569:CAALSH>2.0.CO;2.

- X. Xu, M. Barlage, R. Rasmussen, S. Shen, S. Miao, and G. Zhou, 2018: Memory of irrigation effects on hydroclimate and its modeling challenge. Environ. Res. Lett., 13, 064009, https://doi.org/10.1088/1748-9326/AAB9DF. 


\section{Earth Interactions - Volume 24 (2020) - Paper No. 1 • Page 24}

Cook, B. I., M. J. Puma, and N. Y. Krakauer, 2010: Irrigation induced surface cooling in the context of modern and increased greenhouse gas forcing. Climate Dyn., 37, 1587-1600, https:// doi.org/10.1007/s00382-010-0932-x.

DeAngelis, A., F. Dominguez, Y. Fan, A. Robock, M. D. Kustu, and D. Robinson, 2010: Evidence of enhanced precipitation due to irrigation over the Great Plains of the United States. J. Geophys. Res., 115, D15115, https://doi.org/10.1029/2010JD013892.

de Vrese, P., S. Hagemann, and M. Claussen, 2016: Asian irrigation, African rain: Remote impacts of irrigation. Geophys. Res. Lett., 43, 3737-3745, https://doi.org/10.1002/2016GL068146.

Eddy, J. A., C. K. Stidd, W. B. Fowler, and J. D. Helvey, 1975: Irrigation increases rainfall? Science, 188, 279-281, https://doi.org/10.1126/SCIENCE.188.4185.279.

Entekhabi, D., and Coauthors, 2004: The Hydrosphere State (Hydros) satellite mission: An Earth system pathfinder for global mapping of soil moisture and land freeze/thaw. IEEE Trans. Geosci. Remote Sens., 42, 2184-2195, https://doi.org/10.1109/TGRS.2004.834631.

— , and Coauthors, 2010: The Soil Moisture Active Passive (SMAP) mission. Proc. IEEE, 98, 704-716, https://doi.org/10.1109/JPROC.2010.2043918.

Fowler, W. B., and J. D. Helvey, 1974: Effect of large-scale irrigation on climate in the Columbia Basin. Science, 184, 121-127, https://doi.org/10.1126/science.184.4133.121.

Harding, K. J., and P. K. Snyder, 2012: Modeling the atmospheric response to irrigation in the Great Plains. Part I: General impacts on precipitation and the energy budget. J. Hydrometeor., 13, 1667-1686, https://doi.org/10.1175/JHM-D-11-098.1.

Huang, X., and P. Ullrich, 2016: Irrigation impacts on California's climate with the variable-resolution CESM. J. Adv. Model. Earth Syst., 8, 1151-1163, https://doi.org/10.1002/2016MS000656.

Kang, S., and E. B. Eltahir, 2018: North China Plain threatened by deadly heatwaves due to climate change and irrigation. Nat. Commun., 9, 2894, https://doi.org/10.1038/s41467-018-05252-y.

Kueppers, L. M., and M. A. Snyder, 2012: Influence of irrigated agriculture on diurnal surface energy and water fluxes, surface climate, and atmospheric circulation in California. Climate Dyn., 38, 1017-1029, https://doi.org/10.1007/s00382-011-1123-0.

—, M. Snyder, and L. C. Sloan, 2007: Irrigation cooling effect: Regional climate forcing by landuse change. Geophys. Res. Lett., 34, L03703, https://doi.org/10.1029/2006GL028679.

Kugler, J., and T. Woodward, 2006: Crop profile for alfalfa in Washington. USDA National Institute of Food and Agriculture, accessed 16 October 2019, https://ipmdata.ipmcenters.org/ documents/cropprofiles/WAalfalfa.pdf.

Kumar, S. V., and Coauthors, 2006: Land information system: An interoperable framework for high resolution land surface modeling. Environ. Modell. Software, 21, 1402-1415, https://doi.org/ 10.1016/j.envsoft.2005.07.004.

Kunkel, E. K., L. E. Stevens, S. E. Stevens, L. Sun, E. Janssen, D. Wuebbles, K. T. Redmond, and J. G. Dobson, 2013: Regional climate trends and scenarios for the U.S. National Climate Assessment: Part 6. Climate of the Northwest U.S. NOAA Tech. Rep. NESDIS 142-6, 77 pp, https:// www.nesdis.noaa.gov/sites/default/files/asset/document/NOAA_NESDIS_Tech_Report_142-6Climate_of_the_Northwest_U.S.pdf.

Lawston, P. M., J. A. Santanello Jr., B. F. Zaitchik, and M. Rodell, 2015: Impact of irrigation methods on land surface model spinup and initialization of WRF forecasts. J. Hydrometeor, 16, 1135-1154, https://doi.org/10.1175/JHM-D-14-0203.1.

,,-- T. E. Franz, and M. Rodell, 2017: Assessment of irrigation physics in a land surface modeling framework using non-traditional and human-practice datasets. Hydrol. Earth Syst. Sci., 21, 2953-2966, https://doi.org/10.5194/hess-21-2953-2017.

Lobell, D. B., and C. Bonfils, 2008: The effect of irrigation on regional temperatures: A spatial and temporal analysis of trends in California, 1934-2002. J. Climate, 21, 2063-2071, https:// doi.org/10.1175/2007JCLI1755.1.

—, G. Bala, A. Mirin, T. Phillips, R. Maxwell, and D. Rotman, 2009: Regional differences in the influence of irrigation on climate. J. Climate, 22, 2248-2255, https://doi.org/10.1175/ 2008JCLI2703.1. 


\section{Earth Interactions • Volume 24 (2020) • Paper No. 1 • Page 25}

Mahmood, R., K. G. Hubbard, and C. Carlson, 2004: Modification of growing season surface temperature records in the northern Great Plains due to land-use transformation: Verification of modelling results and implication for global climate change. Int. J. Climatol., 24, 311-327, https://doi.org/10.1002/joc.992.

— S. A. Foster, T. Keeling, K. G. Hubbard, C. Carlson, R. Leeper, 2006: Impacts of irrigation on 20th century temperature in the northern Great Plains. 54, 1-18, https://doi.org/10.1016/ j.gloplacha.2005.10.004.

Martinez-Austria, P. F., and E. R. Bandala, 2017: Temperature and heat-related mortality trends in the sonoran and Mojave Desert region. Atmosphere, 8, 53, https://doi.org/10.3390/ atmos 8030053 .

Menne, M. J., I. Durre, R. S. Vose, B. E. Gleason, and T. G. Houston, 2012a: An overview of the Global Historical Climatology Network-Daily database. J. Atmos. Oceanic Technol., 29, 897-910, https://doi.org/10.1175/JTECH-D-11-00103.1.

— sion 3.24. NOAA National Climatic Data Center, accessed 27 June 2018, http://doi.org/ 10.7289/V5D21VHZ.

Nakanishi, M., and H. Niino, 2006: An improved Mellor-Yamada Level-3 model: Its numerical stability and application to a regional prediction of advection fog. Bound.-Layer Meteor., 119, 397-407, https://doi.org/10.1007/s10546-005-9030-8.

NASS, 2014: 2012 census of agriculture: Farm and ranch irrigation survey (2013). Vol. 3, Special studies, Part 1. USDA NASS Rep. AC-12-SS-1, 266 pp., https://www.nass.usda.gov/Publications/ AgCensus/2012/Online_Resources/Farm_and_Ranch_Irrigation_Survey/fris13.pdf.

NCEI, 2019: Data tools: 1981-2010 normals. National Oceanic and Atmospheric Administration, accessed 10 June 2019, https://www.ncdc.noaa.gov/cdo-web/datatools/normals.

O’Neill, P. E., S. Chan, E. G. Njoku, T. Jackson, and R. Bindlish, 2018: SMAP Enhanced L3 Radiometer Global Daily $9 \mathrm{~km}$ EASE-Grid Soil Moisture, version 1. NASA National Snow and Ice Data Center Distributed Active Archive Center, accessed 18 June 2018, https:// doi.org/10.5067/RFKIZ5QY5ABN.

Ozdogan, M., M. Rodell, H. K. Beaudoing, and D. L. Toll, 2010: Simulating the effects of irrigation over the United States in a land surface model based on satellite-derived agricultural data. J. Hydrometeor., 11, 171-184, https://doi.org/10.1175/2009JHM1116.1.

Pei, L., N. Moore, S. Zhong, A. D. Kendall, D. W. Hyndman, and Z. Gao, 2016: Effects of irrigation on the summer climate over the United States. J. Climate, 29, 3541-3558, https://doi.org/ 10.1175/JCLI-D-15-0337.1.

Peters-Lidard, C. D., and Coauthors, 2015: Integrated modeling of aerosol, cloud, precipitation and land processes at satellite-resolved scales. Environ. Modell. Software, 67, 149-159, https:// doi.org/10.1016/j.envsoft.2015.01.007.

Qian, Y., M. Huang, B. Yang, and L. K. Berg, 2013: A modeling study of irrigation effects on surface fluxes and land-air-cloud interactions in the southern Great Plains. J. Hydrometeor, 14, 700-721, https://doi.org/10.1175/JHM-D-12-0134.1.

Rodell, M., P. R. Houser, A. A. Berg, and J. S. Famiglietti, 2005: Evaluation of 10 methods for initializing a land surface model. J. Hydrometeor, 6, 146-155, https://doi.org/10.1175/JHM414.1.

Salmon, J. M., M. A. Friedl, S. Frolking, D. Wisser, and E. M. Douglas, 2015: Global rain-fed, irrigated, and paddy croplands: A new high resolution map derived from remote sensing, crop inventories and climate data. Int. J. Appl. Earth Obs. Geoinf., 38, 321-334, https://doi.org/ 10.1016/j.jag.2015.01.014.

Santanello, J. A., C. D. Peters-Lidard, and S. V. Kumar, 2011: Diagnosing the sensitivity of local land-atmosphere coupling via the soil moisture-boundary layer interaction. J. Hydrometeor., 12, 766-786, https://doi.org/10.1175/JHM-D-10-05014.1.

— — - A. Kennedy, and S. V. Kumar, 2013: Diagnosing the nature of land-atmosphere coupling: A case study of dry/wet extremes in the U.S. southern Great Plains. J. Hydrometeor., 14, 3-24, https://doi.org/10.1175/JHM-D-12-023.1. 


\section{Earth Interactions • Volume 24 (2020) • Paper No. 1 • Page 26}

— - and Coauthors, 2018: Land-atmosphere interactions: The LoCo perspective. Bull. Amer. Meteor. Soc., 99, 1253-1272, https://doi.org/10.1175/BAMS-D-17-0001.1.

— , P. Lawston, S. Kumar, and E. Dennis, 2019: Understanding the impacts of soil moisture initial conditions on NWP in the context of land-atmosphere coupling. J. Hydrometeor., 20, $793-$ 819, https://doi.org/10.1175/JHM-D-18-0186.1.

Simonds, W. J., and T. R. Linenberger, 1998: The Columbia Basin Project. U.S. Bureau of Reclamation, accessed 2 February 2005, 89 pp., https://www.usbr.gov/pn/grandcoulee/pubs/ cbhistory.pdf.

Sorooshian, S., J. Li, K. Hsu, and X. Gao, 2011: How significant is the impact of irrigation on the local hydroclimate in California's Central Valley? Comparison of model results with ground and remote-sensing data. J. Geophys. Res., 116, D06102, https://doi.org/10.1029/ 2010JD014775.

Stidd, C. K., 1967: Local moisture and precipitation. University of Nevada Desert Research Institute Preprint Series 45, $34 \mathrm{pp}$.

Svoboda, M., and Coauthors, 2002: The Drought Monitor. Bull. Amer. Meteor. Soc., 83, 1181-1190, https://doi.org/10.1175/1520-0477-83.8.1181.

Thiery, W., E. L. Davin, D. M. Lawrence, A. L. Hirsch, M. Hauser, and S. I. Seneviratne, 2017: Present-day irrigation mitigates heat extremes. J. Geophys. Res. Atmos., 122, 1403-1422, https://doi.org/10.1002/2016JD025740.

Tuinenburg, O. A., and J. P. R. de Vries, 2017: Irrigation patterns resemble ERA-Interim reanalysis soil moisture additions. Geophys. Res. Lett., 44, 10341-10 348, https://doi.org/10.1002/ 2017GL074884.

USBR, 2008: Reclamation-Managing water in the West: The story of the Columbia Basin Project. Accessed 15 June 2018, 3 pp., https://www.usbr.gov/pn/project/brochures/ columbiabasinproject.pdf.

—_, 2016: AgriMet: Cooperative Agricultural Weather Network. Accessed 10 June 2018, https:// www.usbr.gov/pn/agrimet/general.html.

Vose, R. S., and Coauthors, 2014: NOAA's Gridded Climate Divisional Dataset (CLIMDIV). NOAA National Climatic Data Center, accessed 16 January 2017, https://doi.org/10.7289/ V5M32STR.

Wan, Z., 2013: Collection-6 MODIS land surface temperature products users' guide. USGS-NASA LP DAAC, accessed 6 December 2016, 33 pp., https://lpdaac.usgs.gov/documents/118/ MOD11_User_Guide_V6.pdf.

Weather Underground, 2019: Tri-Cites Airport, Washington monthly history. Accessed 10 June 2019, https://www.wunderground.com/history/monthly/KPSC/date/2015-7?req_city =Kennewick\&req_ state $=$ WA\&req_statename $=$ Washington\&reqdb.zip $=99336 \&$ reqdb.magic $=1 \&$ reqdb.wmo $=99999$.

Wei, J., P. Dirmeyer, D. Wisser, M. G. Bosilovich, and D. M. Mocko, 2013: Where does the irrigation water go? An estimate of the contribution of irrigation to precipitation using MERRA. J. Hydrometeor., 14, 275-289, https://doi.org/10.1175/JHM-D-12-079.1.

Xia, Y. L., and Coauthors, 2012: Continental-scale water and energy flux analysis and validation for the North American Land Data Assimilation System project phase 2 (NLDAS-2): 1. Intercomparison and application of model products, J. Geophys. Res., 117, D03109, https:// doi.org/10.1029/2011JD016048

Yang, Z., F. Dominguez, X. Zeng, H. Hu, H. Gupta, and B. Yang, 2017: Impact of irrigation over the California Central Valley on regional climate. J. Hydrometeor, 18, 1341-1357, https:// doi.org/10.1175/JHM-D-16-0158.1.

Earth Interactions is published jointly by the American Meteorological Society, the American Geophysical Union, and the Association of American Geographers. For information regarding reuse of this content and general copyright information, consult the AMS Copyright Policy (www.ametsoc.org/PUBSReuseLicenses). 